\title{
TRISTÁN Y LA LITERATURA RÚSTICA ESPAÑOLA
}

Carlos Villanueva

Universidade de Santiago de Compostela

Aunque hemos hablado colateralmente en otras ocasiones de esta notable conferencia pronunciada por Víctor Said Armesto en el Ateneo (Villanueva, 2010; Villanueva, 2014), es la primera vez que publicamos el texto íntegro; tratando, al tiempo, de explicar su éxito como orador y como hombre de ciencia, así como el eco y trascendencia que el "Tristán rústico" alcanzó en los medios de comunicación, en las tertulias y en la propia correspondencia del pontevedrés. Leyendo el texto, declamándolo y analizándolo, no acabamos de comprender el enorme impacto que tuvo, sólo explicable si sumamos (a) circunstancias contextuales (el estreno de Tristán, de Wagner, una semana antes, con mareas de entusiasmo y toda la riada teórica sobre italianismo y wagnerianismo vertida en prensa y en revistas de música); (b) sus virtudes personales en la transmisión (tanto por la reconocida categoría de Said como exquisito orador, como por la novedad de la orientación wagneriana del escrito); (c) y la preparación del ambiente, por el propio Víctor, de lo que sería el punto de partida mediático de su soñada cátedra de Literatura galaico-portuguesa: creada en la Universidad Central, por él y para él, y conseguida, no sin esfuerzo, en 1914 (cfr. Alonso Montero, 2014; Casas, 2015; Mascato, 2015). Así se gestó (y se gestionó), con acciones y circunstancias, la tormenta perfecta.

Tenemos que retroceder en el calendario un año -febrero de 1910-, para apuntalar los factores "climáticos" que confluyeron: en primer lugar, y a través de la correspondencia de Víctor con Menéndez Pelayo con la petición de mediación (Villanueva, 2011), conocemos el plan de Said de que se dote la cátedra, al tiempo que le es concedida una pensión de la Junta de Ampliación de Estudios para completar los materiales del romancero que venia recopilando ${ }^{1}$ y que, en parte, volcará en el "cancionero" que presentará, junto con Casto Sampedro, al Concurso de la Academia de San Fernando, -que ganarán por unanimidad-, según le adelanta su amigo Conrado del Campo en carta de 8 agosto de aquel año².

Ya en otoño de aquel mismo año, la prensa madrileña, de manera orquestada, inicia una campaña a favor de Said y de la dotación de las cátedras de literatura catalana y gallego-portuguesa $^{3}$. El apoyo en prensa se amplificó notablemente con la propuesta parlamentaria de Eduardo Vincenti y de Giner de los Ríos ${ }^{4}$, y con el telegrama de la Academia Gallega al Ministro de Instrucción Pública a favor de la cátedra en apoyo de la propuesta, que la prensa filtró estratégicamente:

La Junta de Gobierno de la Real Academia Gallega testimonia a V. E. su gratitud y su aplauso por haber aceptado la enmienda para la creación de la cátedra de Lengua y Literatura galaico-portuguesa de la Universidad Central, prestando así un inmenso servicio a la cultura general. Galicia ve satisfecha una de sus mayores aspiraciones, viendo que se trata de conocer su gloriosa historia literaria. Esta Junta reitera a V.E. su entusiasta felicitación por el nobilísimo acuerdo. Presidente, Murguía. Secretario, Carré5.

Ni que decir tiene, la enorme polémica que en la Universidad Compostelana generó la iniciativa parlamentaria "centralista" y el apoyo de Murguía (Mascato, 2015), lo que hizo aconsejable la primera de las muchas "cartas al director/ los abajo firmantes" que flanquearían todo aquel proceso; el argumento era obvio: ¿dónde mejor que Madrid para asentar y promocionar la lengua gallega y su literatura?:

Como gallegos que somos, y preferentemente dedicados al estudio de las letras, creemos indecli- 
nable deber adherirnos al mensaje de gracias elevado por la Real Academia Gallega al Ministro de Instrucción Pública y a las doctas manifestaciones publicadas por el señor Vincenti en "El Imparcial", a propósito de la fundación de una cátedra galaico-portuguesa en la Facultad de Filosofía y Letras de la Universidad de esta corte. $Y$ hacemos constar, con especial ahínco, que el hecho de haberse emplazado en la Capital de España honra a nuestra región, pues que con ello se acredita que el estudio de nuestras letras atañe a la cultura patria.

Fdo./ Sofía Casanova, Alfredo Vicenti, Manuel Linares Rivas, Ramón del Valle-Inclán, José Rodríguez Mourelo, Javier Vales Failde, Waldo A. Insúa, Emilio Fernández-Vaamonde, Manuel de Saralegui y Medina, Alberto Insua, Javier Valcarce, Enrique Amado, Prudencio Canitrot, Luis Antón de Olmet, Basilio Álvarez, Julio Prieto Villabrille, Daniel López Orense, Carlos Miranda, Vicente Casanova, Gonzalo Seijas, Alfonso Alcalá Martín, Prudencio Iglesias, Ricardo R. Vilariño, Santiago Román Prieto- (siguen más firmas) ${ }^{6}$.

Los pasos parlamentarios, con apoyos en la sombra de Montero Ríos, Eduardo Vincenti, Julio Burell o Augusto González Besada, entre otros, se fueron dando, bajo la atenta mirada de Alfredo Vicenti, desde su propio periódico, El Liberal.

\section{La aventura de Tristán}

Said Armesto, a la altura del calendario de las pretensiones académicas que narramos, aún no había defendido su tesis doctoral, algo que no sucederá hasta el 31 de junio de 1911, cuyo tema, precisamente, versará sobre La materia de Bretaña ${ }^{7}$. Ni que decir tiene que todo este abundantísimo material tristanesco recopilado para su tesis, a tenor los manuscritos que se conservan en el Fondo Said de la Fundación Barrié, y en paralelo a sus pesquisas romancísticas, será la base de donde salgan sus erutitas referencias, las conexiones intertextuales, las enjundiosas citas, los argumentos de las polémicas y, en suma, el vivero que le permitiría mostrar y demostrar su enorme solvencia y atractivo ante el mundo académico, a la altura de los grandes filólogos y eruditos.

El discurso de Ateneo, que transcribimos, al igual que su tesis doctoral, publicada como memoria aquel año $1911^{8}$, las originales notas para el programa del estreno en el Real de Tristan e Isolda, que comentamos más adelante, o las conferencias en los Cursos para extranjeros, invitado por la Junta de Ampliación de Estudios, aparte de recensiones varias y colaboraciones en prensa, salen de este enorme fondo de armario que Said usaría en el futuro y que, sin duda, habría sido el material para una monografía posterior, anunciada pero que nunca llegó a concretar.

\section{Tristán e Iseo en el Real y en el Ateneo}

La marea de entusiasmo que se produjo en Madrid tras el estreno de Tristán e Isolda, y que derivó en la constitución, tardía y desenfocada, de la Asociación Wagneriana9 ${ }^{9}$, supuso la primera ocasión a Said mostrar urbi et orbi su profundo concimiento sobre la materia. Su amigo Luis París, empresario y promotor desde el Real de la obra, le encargó unas notas que acompañarían a la traducción del libreto ${ }^{10}$ :

Mi querido Víctor; hace seis u ocho días escribí a usted -carta certificada- pidiéndole unas cuartillas... Ya sé que esa es una [tarea] un poco molesta, pero las necesito con urgencia porque el folleto está en prensa y la obra se estrena el 15. I No me olvide pues y remítamelo lo antes posible.

Gracias otra vez y un abrazo de su viejo camarada que lo quiere mucho, mucho.

Luis [París] Empresa del Teatro Reall Madrid 7 de enero de $1911^{11}$.

Said, desde la casa de sus suegros en Cuñas (Orense) le mandó a vuela pluma una síntesis de la conferencia que preparaba, "Tristán y la literatura rústica española", con la que triunfaría en el Ateneo pocos días más tarde del estreno del Real' ${ }^{12}$. Fueron intérpretes de aquella memorable velada del Tristán Cecilia Cagliardi y Francisco Viñas, bajo la dirección de Gino Marinuzzi.

Aprovechando el gran ambiente wagneriano, que en torno al Tannhäuser y a Tristán e Iseo se había creado, el presidente de la sección de literatura del Ateneo, Julio Burell ${ }^{13}$, le propuso a Said aprovechar el entusiasmo con una conferencia dentro de un ciclo literario en el que también tomarían parte Ramón Pérez de Ayala, Enrique Amado y Fernando Fortún, entre otros. Así lo reflejaba la prensa: 
Acordóse, en primer término, invitar á los literatos más revelantes para que ocupen la cátedra del Ateneo, organizándose a este efecto una serie de conferencias sobre especialidades literarias. Ya está anunciada la primera de ellas, que corre á cargo de uno de nuestros eruditos de verdad, Víctor Said Armesto. Este nombre y el asunto del tema, «Tristán y la Literatura rústica española», interesante como pocos, hoy de actualidad vivisima, harán que el viernes 17 del corriente se congreguen todos los buenos aficionados á las Letras en los amplios salones del Ateneo ${ }^{14}$.

A los aplausos de la prensa por la originalidad y novedad del tema -el tránsito del mítico personaje por la literatura rural gallega y española- se sumaron los elogios generalizados por su sorprendente capacidad oratoria, la belleza de las imágenes y su orientación erudita; así lo cuenta Luis Bello:

(...) Para todos, aún para los ateneístas capaces de seguir la labor de Said Armesto, fue una sorpresa oír el comienzo de una exposición sencillísima, toda claridad, toda transparencia galana de forma, como corresponde a un ensayo literario, pero precisa y limpia de retórica con la severidad que impone la cátedra. No trataba sino de ofrecer un manojo de florecillas silvestres, de lays y canciones populares a la memoria del maestro de Bayreuth que supo dar expresión más intensa al poema de Tristán e Iseo.

Para ello, buscó la leyenda en sus orígenes, recogió el eco de las montañas celtas en las colinas de Galicia; y lo hizo con una cultura tan certera y un amor tan hondo a la huella del sentimiento popular, que el público se dejó traspasar de la misma emoción. Las poesías castellanas y gallegas, leídas con arte delicado y con práctica no improvisada, arrancaron aplausos. Todos aplaudimos en Said Armesto la visión de la época y el tino para extraer lo que hay de eterno en el poema vulgar ${ }^{15}$.

También Javier Bueno, desde El Radical de Madrid, se sumaba a los elogios:

(...) Yo le oía la otra tarde hablar de la leyenda de Tristán y de nuestros cantos populares. No sé cómo poco a poco el conferenciante fue maniobrando en mi interior, lo único que puedo decirles es que al terminar salía yo del Ateneo haciendo la apología del erudito. Armesto supo aderezar su erudición con tan gran cantidad de ingenio, de belleza, de buen gusto y de amenidad, que el odio que tanto me distraía había desaparecido ${ }^{16}$.
Murguía se hace eco del éxito, comentándole otras cosas referentes al premio del Cancionero de la Academia de San Fernando, a la cátedra, y a la polémica generada en Galicia por este asunto:

Mi querido Víctor; ayer recibí la visita de un amigo que venía de Madrid y me verificó entusiasmado el hermoso triunfo que has alcanzado, en tu Conferencia en el Ateneo. Aparte de ser cosa tuya y por tanto satisfacerme por completo el éxito que alcanzaste, me alegro de él por lo que habrá dolido a ciertas almas, doblemente mezquinas por lo envidiosas y pequeñas, para las cuales, solo ellas merecen triunfos y felicidades.

Desde que recibí tu última contándome tu lucha en esa, a la cual no contesté porque no sabía en donde te hallabas, tenía vivísimos deseos de enterarte de algo que te conviene saber, para no ignorar la doblez de ciertas gentes con que uno tropieza en el mundo.

Te extrañabas de que Fernando Martínez hubiese trabajado contra tí en el asunto de la cátedra, enviando sueltos a los periódicos de Santiago. Más te extrañarás de su padre a quien tanto estimas, que anduvo en tal ocasión pretendiendo que se reuniese la Academia y diese a la Junta de Gobierno un voto de censura por el telegrama de Burel (sic) y acordase pedir la cátedra para Santiago. Gracias a nuestra marcha a Vigo no pasó nada, de lo contrario, hubiéramos sufrido un mal rato y algo más.

Teniendo en cuenta y conociendo a los señores, referí en la correspondencia que tenemos con la Asociación Protectora de la Academia en la Habana, lo que habíamos hecho, exponiéndole las razones que a ello nos habían inclinado y tuvimos la satisfacción de ver aprobada nuestra conducta, añadiendo que te escribirán y felicitarán, no sé si por lo de la cátedra, si por el premio de las canciones populares. Recibe también por estas mi felicitación. D. Casto no habrá salido de su apoteosis! Debo advertirte que la Junta celebrada en Vigo, se aprobó lo hecho por la Junta de Gobierno, y con eso tapiamos la boca a los rebeldes. (...) Cor[uña] 22 de febrero de $1911^{17}$.

Como indicábamos, pocos meses más tarde defendía su tesis doctoral en la Universidad Central, precisamente sobre el tema cenital de sus investigaciones: Notas para el estudio de la materia de Bretaña.

La aclamada intervención de Said en el Ateneo venia ser el eco erudito y competente de 
un asunto que desde varios atrás, tras el éxito de Lohengrin y Tannhäuser, y desde ahora, con Tristán e Iseo, venía discutiéndose entre la intelectualidad española, especialmente a partir de la normalización y mejoría de la producciones wagnerianas en España ${ }^{18}$. Wagner acabó convirtiéndose para muchos, entre otros la Condesa de Pardo Bazán, Alfredo Vicenti, Ramón Arana, y tantos otros amigos de Víctor y gallegos de pro, en una alternativa al teatro italiano y en una fuente de inspiración para el teatro regional; y no resulta extraño que el propio Said hiciera su ensayo wagneriano con La flor del agua, escogiendo a Conrado del Campo para poner música a su hermoso libreto (Trillo y Villanueva, 2013; Villanueva, 2014).

Finalmente, la figura de Tristán, con todo el profundo misterio y encanto que encerraba el heredero de Orfeo, fue también tema predilecto de tertulias y conferencias a cargo de los nuevos teósofos de Madame Blavatsky, liderados en España por Mario Roso de Luna, que por aquellas fechas adelanta en sus conferencias un libro sobre Wagner teósofo que alcanzaría enorme trascendencia en España y destacada presencia en sus charlas del Ateneo ${ }^{19}$.

\section{El documento que transcribimos y sinopsis}

El discurso, que se conserva en el Fondo Said de la Fundación Barrié, de 32 pgs., papel/ octaviIla, fue, sin duda, el manuscrito que Víctor puso sobre el atril. De esas 32 páginas seis de ellas están repetidas (con variantes, tachaduras, añadidos, etc.) lo que permitiría, en caso de querer hacer una reconstrucción diplomática, ponerlas en paralelo para comprobar las variantes que en esas semanas de preparación Said fue introduciendo al texto inicial. Hemos tratado de transcribir, pues, el discurso pronunciado, no la evolución del mismo, lo que exigiría una edición crítica.

Obviamente, el texto está concebido para ser declamado -no para ser impreso-, si tenemos en cuenta las abundantes frases retóricas, las bromas anotadas (como si fueran espontáneas), la captatio inicial, o las reiteraciones y énfasis presentes habitualmente en un texto hablado. Aunque nuestra transcripción no permite ni el color ni los matices que comprobamos en el ori- ginal, resultan determinantes y de gran valor (al menos para podernos imaginar el vuelo retórico de ese "maravilloso discurso" de Said tan alabado por los asistentes al acto) los diferentes tipos de subrayado, en lápiz negro, azul o rojo; los subrayados sencillos, dobles o triples: en nombres de personajes, cambios de temática en el discurso, o frases enfáticas que quiere tener muy a la vista. En todo caso, y teniendo en cuenta la tan celebrada memoria fotográfica de Said, capaz de recitar romances, canciones o textos de referencia sin mirar al papel, es seguro que fue un discurso memorizado, con el rabillo del ojo puesto en las señales, en los colores, en los tipos de subrayado, etc., algo habitual en los apuntes de Said (como estudia E. Lavaud, 1972). Ante la imposibilidad de usar color, hemos optado por el subrayado convencional.

Sin duda, esta conferencia / discurso es una síntesis para un público culto, con muchos referentes literarios y filosóficos, y entregado a la causa wagneriana; obviamente no tiene notas y se queda, en su planteamiento y desarrollo, con ciertas lagunas, al no pretender el conferenciante entrar en las polémicas teóricas, en las diatribas académicas y en tantos y tantos asuntos que sí desarrollará en su tesis La materia de Bretaña. En realidad, la música de fondo que está sonando en la emoción general de los ateneístas es la de Wagner, que se había escuchado unos días antes en el Teatro Real. Por tando, lo que ahora leemos, ciento cuatro años después, puede resultar "escaso", debiendo completarse con la emoción, aún viva en el público asistente, de los ecos de la historia de amor nunca antes mejor contada, y declamada apasionadamente, con el encanto y la pericia de uno de los mejores oradores de su tiempo.

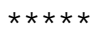

Said Armesto en su discurso no hace otra cosa que poner en paralelo la historia del triángulo amoroso (Marke, Tristán e Isolda) con la variedad y riqueza de las versiones celtas, bretonas, francesas y peninsulares que se trasladan al mundo rural de los cuentos y de los romances populares.

Toma, como punto de partida, el entierro de la pareja en Cornuallles, que en espejo es reco- 
gido por aquel romance de Bernaldino e Sabeliña, que Alejandra Murguía le había pasado a Víctor Said para su colección ${ }^{20}$. El pontevedrés, gran conocedor de la literatura universal y de las estelas romancísticas, recordará a los asistentes las distintas referencias de esta temática de los amantes enterrados, tanto en la literatura popular como en la culta y en el romance: desde el cuento Sabel de Doña Emilia ${ }^{21}$, a los romances sefardíes, portugueses o castellanos; en todo caso, como ya se ha dicho (Axeitos y Carballal. 2005: 97), esta temática fue recogida, con anterioridad, por Marcial de Valladares, Saco y Arce o Pérez Ballesteros, variantes que Doña Emilia conocía a través de los fondos de la Sociedad de Folk-lóre Gallego, que ella misma presidía.

Plantea Said la confluencia, ya en el siglo XV, de las corrientes rural y la erudita, trasladándose en verso culto muchos de estos temas, ahora en cancioneros y en nuevos romances, como en éste de la colección de Juan de Rivera, que también aparece en el repertorio gallego:

Ferido está $D$. Tristán - de una mala lanzada diósela el rey su tío - por celos que d'el cataba. El fierro tiene en el cierdo - de fuera le tiembla el asta.

Valo a ver la reina Iseo - por la su desdicha mala. Júntanse boca con boca - cuanto una misa rezada. Llora el uno, llora el otro - la cama bañan en aguas. [....]

Aquí recupera Said el simbolismo de la azucena, con evidente contenido sexual, tema presente en muchas variantes gallegas:

Alli nace un arboledo - que azucena se llamaba. Cualquier mujer que la come - luego lqueda embarazada ${ }^{22}$

Comiéra la Reina Iseo - por la su desdicha mala. Júntanse boca con boca - cuanto una misa rezada. Llora el uno, llora el otro - la cama bañan en aguas. Alli nace un arboledo - que azucena se llamaba. [...]

La azucena y su simbolismo aparece en romances asturianos, portugueses, cántabros o gallegos como han estudiado J. M. Pedrosa (2014) y otros; en todo caso, insiste varias veces Said en el gran interés y acogida del Norte peninsular por estos asuntos, menos presentes, sin duda, en el área castellana.
Otro tema de gran trascendencia en el discurso del Ateneo es el del personaje de Morolt/ Moroult, muerto en duelo por la espada de Tristán, que pasa a la leyenda como el que recauda para Irlanda el tributo de cien doncellas, cien mancebos y cien caballos, y que la tradición hispana traslada a los árabes, como se recoge en el romance que ya fray Martín Sarmiento trae a colación del apellido Figueirido, un tema que Said tratará en su correspondencia con Murguía, que le había facilitado muchos materiales para su romancero y para su tesis ${ }^{23}$.

Un tercer tema del que Said nos habla fue el del Santo Grial, relacionándolo con la tradición existente en el Cebrero y que, obviamente, nos remite a la peregrinación, al Camino de Santiago y a los peregrinos francos e ingleses que dejaron aquí sus aportaciones. El texto castellano de la Demanda del Santo Grial circula en parelelo con el romance, muy popular en Galicia, Portugal, Asturias, Santander, y Cataluña. Vemos éste ejemplo biblingüe recogido por el propio Víctor en Pedrafita do Cebreiro y que cita en su discurso:

Por riba de un monte verde - que nunca fuera cerrado

yo viera pasar un hombre - vestido de colorado.

O vestido que levaba - todo o levaba manchado

que llo manchou Jesucristo - con sangre de s[e] u costado.

La sangre que de él caía - cayó en un cáliz sagrado el hombre que de él bebiera - será bienaventurado.

N'este mundo serás rey - n'el otro rey coronado ${ }^{24}$.

El asunto del Grial -en palabras de Said- no se tomó de libros, sino de tradiciones orales. La empresa de las Cruzadas contribuyó a la difusión; lo mismo que las guerras de conquista, las bodas de príncipes, el amor a la aventura, las peregrinaciones y otras mil historias que esparcieron por el mundo estas leyendas, muchas de las cuales nos sorprende encontrar en textos tan antiguos como el Turpinus, escrito en Santiago de Compostela a mediados del XII; tal es la leyenda bretona, reproducida dos siglos después en la traducción castellana del Caballero Cifar, ubicada en la ciudad de Lucerna, que hoy los campesinos gallegos localizan en diversas comarcas de Doniños, en Carragal y en la laguna de Santa Cristina, en mil partes, en fin -como 
Said nos recuerda: "[...] la invocación de Carlomagno a Santiago, y de improviso, los muros de la ciudad maldita se desploman, y las torres caen, y la ciudad se abisma en las entrañas de la tierra, convirtiéndose en un profundo lago de aguas negras, en cuyo fondo moran peces más negros que las aguas" 25 .

En todo caso, Said insiste en su discurso en el peso que el ciclo celta y bretón tuvo en Galicia, con más intensidad y energía que en Castilla, en donde -según nos dice- "nunca gozó de preferente favor".

Said Armesto sueña con esa trascendencia del género poético y musical (lo ha dicho en varias ocasiones, en la presentación de sus romances en el Ateneo o del Ciclo Breton, memoria que también defiende académicamente en su oposición a cátedra en 1914): Tristán e Isolda, eje del ciclo bretón, especialmente a partir de la versión de Gottfried de Strasburgo, parece el primer gran ensayo romántico -perfecto a su entender-que consigue llevar al máximo logro la idea filosóficoromántica de que la música es el arte capaz de expresar, mejor que ningún otro, el significado profundo de la existencia. Así lo describe Said al final del discurso del Ateneo de 1911:

Tristán vive, pues, entre nosotros, y la musa rural española lo ha hecho suyo por derecho de conquista, pues que suyas son las remodelaciones a que sometió tantos y tan diferentes episodios de la hermosa leyenda, desde la victoria del mons-

\section{Bibliografía}

Abellán, José Luis (2006): El Ateneo de Madrid. Madrid: La librería.

Alonso Montero, Xesús (2014): "Sobre la cátedra de literatura galaico-portuguesa da Universidade Central (Madrid) que gañou por oposición Víctor Said Armesto en 1914", en D. Rodríguez y O. Tovar (coords.): Victor Said Armesto: a lección dun cidadán libre. A Coruña: Fundación Barrié, pp. 115-122.

Axeitos, Ricardo y Carballal, Patricia (2005): "Sabel ou Bernardo e Sabela", en Dolores Thion (ed.): Hommage à Emilia Pardo Bazán. Cadernos. Rennes Centre d'Etudes Galiciennes, vol 4, pp. 97-106.

Capelan, Montserrat (2015): "El regeneracionismo musical y el modelo wagneriano en la escena mu- truo Moroult, hasta la estrategia de la espada interpuesta entre los cuerpos dormidos de Tristán e Iseo; desde el episodio del cuerpo encantado, hasta el erótico simbolismo de las azucenas, desde el taumatúrgico poder del canto de Tristán, atrayendo desde el mar, en la paz de la noche, a la doncella enamorada, hasta el arbitrio de las cortecitas de encina a que Tristán acude para comunicarse con su ídolo; desde el encuentro y muerte de los dos amantes, hasta el conmovedor y romántico motivo de los árboles que se abrazan sobre sus sepulturas. Estos temas no se han borrado nunca de la memoria popular, y perduran y perdurarán por largo tiempo, ora aislados, ora acoplados con otros, correspondientes a otras obras del ciclo bretón que en la literatura de los siglos medios caminaban siempre de brazo dado con Tristán ${ }^{26}$.

Concluía en un estudio anterior (Villanueva, 1914): "Wagner, asimilando Isolda a la música y Tristán a la poesía, los convierte en el símbolo de la fusión entre música y poesía, estadio preparatorio para el nacimiento de una sociedad comunitaria en la cual el arte y el genio pertenecerán a todos, y la obra de arte será producto y patrimonio del pueblo. Es éste el principio del ideal evasivo en Said y otros tantos idealistas respecto al romance y su música, algo que trasciende el localismo./ Said probará ese mismo modelo, identitario, pasadista y esencializador de tradiciones, en su zarzuela La flor del agua, obra que sintetiza la estética, la didáctica y la ideología de este poderoso pensador gallego".

sical gallega", en C. Villanueva et alt. (eds.): Víctor Said Armesto e o seu tempo: perspectivas críticas. A Coruña: Fundación Barrié, pp. 303-330.

Casas, Arturo (2015): "Said Armesto, historiador comparatista da Literatura galega medieval: descrición e análise crítica do programa presentado para a obtención da cátedra de Literatura galaico-portuguesa na Universidade Central (Madrid, 1914)", en C. Villanueva et alt. (eds.): Víctor Said Armesto e o seu tempo: perspectivas críticas. A Coruña: Fundación Barrié, pp. 623-647.

Castro, Felix Francisco (s/f): Ocultismo y teosofía en Galicia: Enediel Shaiah, Vicente Risco e o grupo Teosófico Marco Aurelio (sin editar).

González Herrán, José Manuel (2014): “Hace cien años: Parsifal, de Wagner, a través de las crónicas 
periodísticas de Emilia Pardo Bazán". Ponencia en el congreso Emilia Pardo Bazán periodista (18511921). Madrid: Universidad Complutense.

Groba, Xavier (2011): O legado musical de Casto Sampedro Folgar (1848-1937): O canto galego de tradición oral. Tese de doutoramento, Univesidade de Santiago. CDs tesis doctorales.

Lavaud, Eliane (1972): "Esbozo de la figura de Víctor Said a través de su biblioteca". El Museo de Pontevedra, XXVI, pp. 40-45.

Martínez Torner, Eduardo y Bal y Gay, Jesús (2007): Cancionero Gallego (estudio crítico de C. Villanueva). Ed. facsimilar. La Coruña: Fundación Barrié.

Mascato, Rosario (2015): "Said Armesto y el proceso para la creación de la cátedra de Literatura Galaico-portuguesa en la Universidad Central de Madrid (1909-1914), en C. Villanueva et alt. (eds.): Víctor Said Armesto e o seu tempo: perspectivas críticas. A Coruña: Fundación Barrié, pp. 593-621.

Ortiz de Urbina, Paloma (2007): Richard Wagner en España. La Asociación Wagneriana de Madrid (1911-1915). Alcalá: Servicio de Publicaciones.

Pedrosa, José Manuel (2014): "El romance de La flor del agua. Discursos, motivos, fórmulas". En C. Villanueva: Said Armesto: una vida de romance. Santiago, servicio de Publicaciones de la Universidad, pp. 299-339.

Roso de Luna, Mario (1915): Beethoven teósofo: un capitulo de la obra El Drama lírico de Wagner y los misterios de la antigüedad. Pontevedra, Tip. Viuda e Hijos de Antúnez, 1915. Reed. Editorial: Eyras, S.A., Madrid, 1984.

- (1987): Wagner. Mitólogo y ocultista. (El drama lírico de Wagner y los misterios de la antigüedad). Madrid: Eyras.
Said Armesto, Víctor (1911): Tristán y la literatura rustica española. Ms. Fondo SA, Fundación Barrié.

- (1997): Poesía popular gallega. Domingo García Sabell (ed.). La Coruña: Fundación Barrié.

Sampedro, Casto (1942), Cancionero Musical de Galicia, reunido por José Filgueira Valverde. Pontevedra, Museo de Pontevedra; $3^{a}$ Ed. Facsimilar (2007) (coord. C. Villanueva), La Coruña: Fundación Barrié.

Trillo, Joam y Villanueva, Carlos (eds.) (2013): Conrado del Campo. La flor del agua. Zarzuela en un acto [libreto de Víctor Said Armesto]. Madrid: ICCMU.

Villanueva, Carlos (2007): "Fuentes y personajes para estudio del Cancionero Musical de Galicia de Casto Sampedro y Folgar", en C. Villanueva (coord.), Cancionero Musical de Galicia reunido por Casto Sampedro, $3^{\mathrm{a}}$ ed. A Coruña: Fundación Barrié, pp. 91-150.

- (2010): "El mito de Tristán en el Romancero gallego de Víctor Said Armesto: los espejos identitarios", en Dolores Barral et alt. (eds.), Mirando a Clío. El Arte español espejo de su historia, vol. III, Santiago de Compostela, Servicio de Publicacións da Universidade de Santiago, pp. 2.114-2.135.

- (2011): "Correspondencia entre Marcelino Menéndez Pelayo y Víctor Said Armesto (1906-1912), Boletín de la Biblioteca de Menéndez Pelayo, LXXXVII, pp. 359-366.

- (2014): Víctor Said Armesto. Una vida de romance. Servicio de Publicacións da Universidade de Santiago de Compostela. 


\section{NOTAS}

${ }_{1}$ Plan de actividades a realizar, borrador ms; Fondo SA, Fundación Barrié.

${ }^{2}$ Fondo SA, Fundación Barrié; cfr. Villanueva, 2007; Fondo CS Museo de Pontevedra, apud Groba, 2011.

3 "Reforma necesaria. Nuevas cátedras", El Radical, 29-10-1910; "Dos cátedras nuevas", La Mañana, 30-101910; La Correspondencia de España, 30-10-1910; "Importante y necesario", El Liberal, 31-10-1910.

4 22-11-1910. Eduardo Vincenti, que con Giner de los Ríos acaba de presentar en el Congreso una proposición para crear en Madrid la cátedra de Literatura galaico-portuguesa y en BarceIona la de Literatura catalana, contesta en larga entrevista en El Imparcial un formulario preparado y resuelto por el propio Víctor Said, según nos consta a partir de los borradores que se conservan en el fondo SA de la Fundación Barrié.

${ }^{5}$ Publicado en El Heraldo de Madrid, 16-11-1910.

${ }^{6}$ El Heraldo, El Imparcial, El Liberal, y otros medios, 25-11-1910.

${ }^{7}$ Siguiendo la estela metodológica comparatista de su exitoso Don Juan, Said emprendió en 1911 la aventura rural del Tristan, en sus Notas para el estudio de la materia de Bretaña, material que, como veremos, convertirá en notas al programa, conferencias y publicaciones, incrementando su fama en los círculos del Ateneo y en la prensa de la capital. La tesis fue defendida el 31 de junio de 1911, según la nota del folleto publicado, ante un tribunal integrado por Antonio Sánchez-Moguel, Adolfo Bonilla San Martín, Cayo Ortega Mayor, José Giles Rubio y Juan G. Garijo, habiendo sido calificada de sobresaliente (CV, Fondo SA, Fundación Barrié).

${ }^{8}$ Víctor Said Armesto: Notas para el estudio de la materia de Bretaña en la poesía lírica gallega de los siglos XIII y XIV. Vicente Rico, Madrid 1911. (Me- moria de su tesis de doctorado defendida en la Facultad de Filosofía y Letras; cfr. borrador ms. con variantes en el Fondo SA, Fundación Barrié).

${ }^{9}$ Fue fundada un mes después del estreno de Tristán e Isolda bajo el impulso del empresario Manuel Cendra, industrial de gran fortuna y amigo de los músicos más notables de la capital: Fernández Arbós, Saco del Valle, Manrique de Lara, Conrado del Campo, Bretón y otros; cfr. Ortiz de Urbina (2007).

${ }^{10}$ Ricardo Wagner, Tristán e Iseo, traducción de Luis París, con apéndice de Said Armesto. Imprenta de Domingo Blanco, Madrid, 1911.

${ }^{11}$ Fondo SA, Fundación Barrié.

${ }^{12}$ El texto enviado para el programa lo hemos reproducido y documentado en anterior ocasión (Villanueva, 2014: 461).

${ }^{13}$ Tras su paso por el Ministerio de Instrucción Pública y Bellas Artes, entre 1910 y 1911, Julio Burell y Cuéllar, que fue diputado por Pontevedra y La Coruña, intervino eficazmente en la sombra en la consecución de la cátedra de Literatura galaico-portuguesa para Said Armesto.

14 "Ateneo de Madrid. Proyectos literarios". La correspondencia de España. 12-2-1911; cfr. C. Villanueva, 2014: 127.

15 Luis Bello, «Sobre la erudición. Con motivo de una conferencia». El Imparcial. Diario liberal (20-2-1911).

${ }^{16}$ Javier Bueno, El Radical de Madrid (recorte de prensa, Fondo SA, Barrié).

\section{${ }^{17}$ Fondo SA, Fundación Barrié.}

${ }^{18} \mathrm{Cfr}$. para el tema de Wagner en Galicia, Capelán, 2015; la investigadora parte de la conferencia de doña Emilia Pardo Bazán en Lugo, en 1906, con ocasión del homenaje a Juan Montes; cfr. también González Herrán, 2014.

${ }^{19}$ Sobre los discursos teosóficos de Mario Roso de Luna en el Ateneo, cfr. Abellán (2006: 107). El 16 de agosto de
1911, pocos meses después de la conferencia de Víctor Said, se constituía en Pontevedra el grupo teosófico "Marco Aurelio", fundado por Alfredo Rodríguez de Aldao, Javier Pintos Fonseca y Jacobo San Martín, nombrando a Mario Roso de Luna Presidente Honorario; editaron en Pontevedra, años más tarde, una de aquellas conferencias del Ateneo de Roso de Luna (1915); cfr. sobre el grupo teosófico pontevedrés, Felix Francisco Castro (s/f).

${ }^{20}$ Recogido en Casto Sampedro (1942: $\left.n^{\circ} 169\right)$

${ }^{21}$ Cfr. Víctor Said Armesto: "Tristán y la literatura rústica española", op. cit. Como bien indican Ricardo Axeitos y Patricia Carballal (2005: 97) no fue Said ni el primero ni el único que lo recogió; podemos buscar más referencias en el propio Said Armesto (1997), o en el cancionero de E. Martínez Torner y Jesús Bal y Gay, Cancionero Gallego (2007), que incorporan nuevas versiones; completadas por las que nos aporta J. M. Pedrosa (2014).

22 "El simbolismo de la azucena, el carácter fálico que ostenta aquí esa flor, lo tomó el poeta del Tristán en prosa, puesto que se liga al pasaje en que Bragania, suplantando a Iseo la noche de sus bodas con el rey Marco, pierde, como dice el texto, una flor de lis, una azucena que llevaba consigo, como que no le ocurre a Iseo, no porque ésta se conserve en la maceta, sino porque ya Tristán se había apoderado de ella, después de regarla con el filtro mágico, la tarde en que los dos navegaban con rumbo a las costas de Cornualles". [apud Said Armesto, Víctor, "Tristán y la literatura rústica española", Op. cit].

${ }^{23} \mathrm{Cfr}$. la carta de Said Armesto a Murguía, de 11-8-1903, refiriendo este romance (Fondo SA/19, Fundación Barrié); la transcribo y comento en Villanueva, 2014.

${ }^{24}$ Víctor Said Armesto: "Tristán y la literatura rústica española", Op. cit.

$$
\begin{aligned}
& { }^{25} \text { Idem. } \\
& { }^{26} \text { Idem. }
\end{aligned}
$$




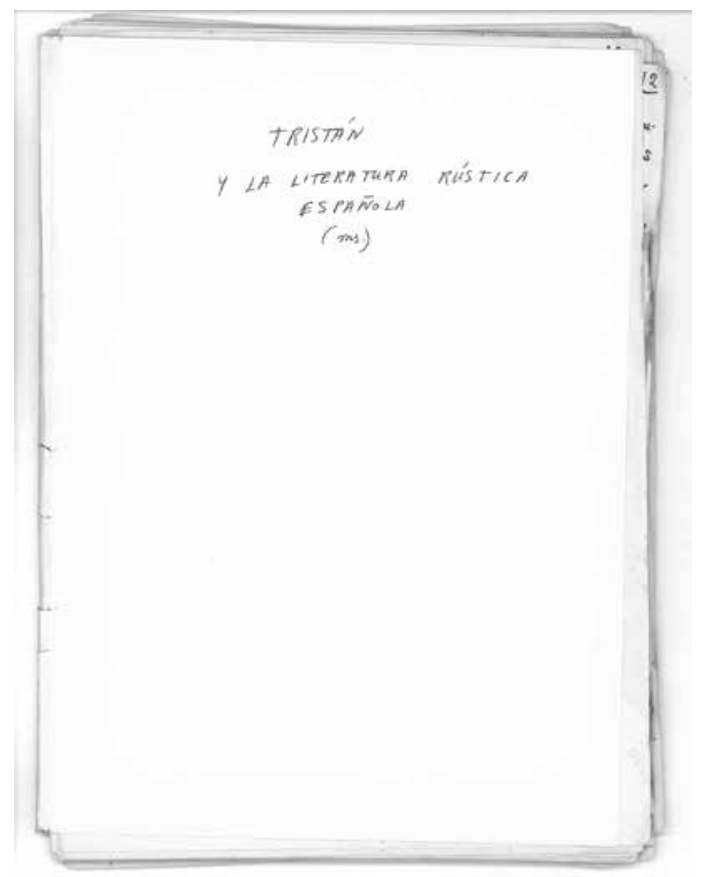

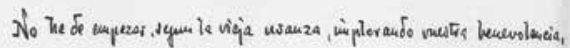

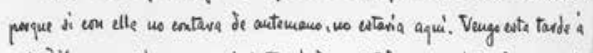

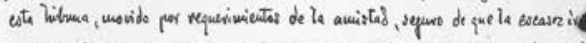

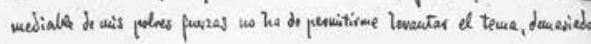

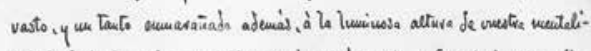

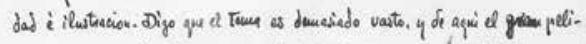

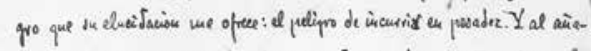

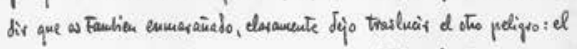

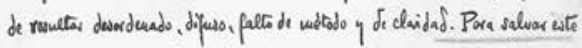

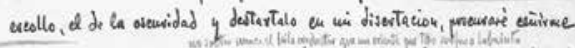

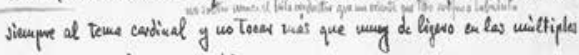

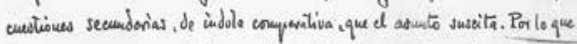

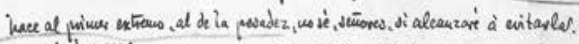

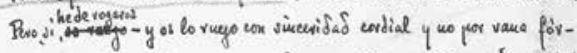

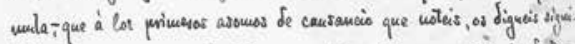

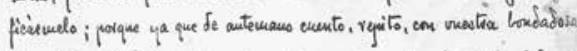
disposiciou de ámimo hacis min, es deber mis correspender à ella. Yuo es

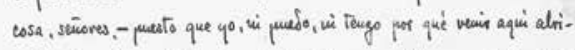

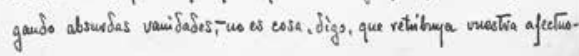

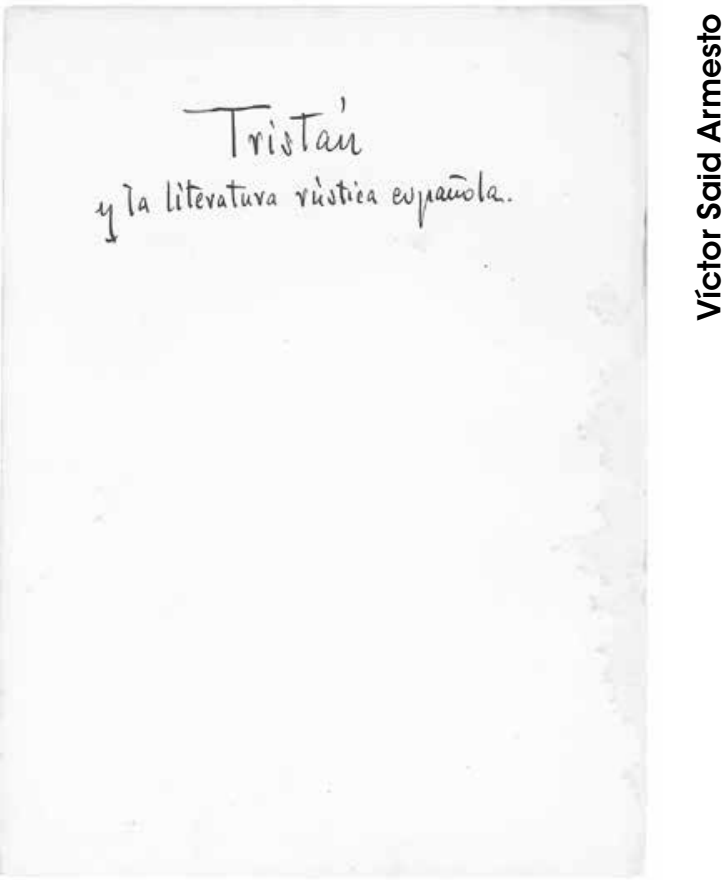

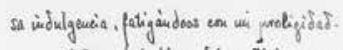

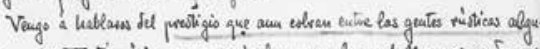
nos tomas del Tritair, del ceo que aqui ales zarou las cabollevereas audarzas

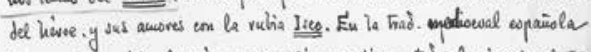

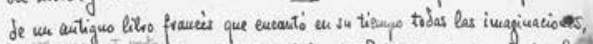

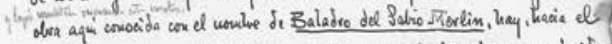

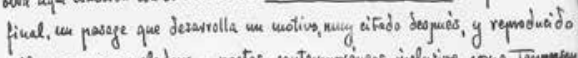

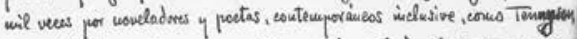
que undio solue ese terua us posenita entaniador: aludo al pasage en que

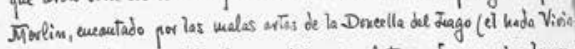

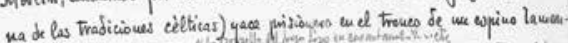

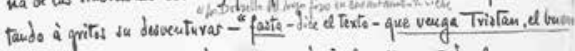
cabolleso, aquel que halia de aruer mas lealucarte que Todos los que aves.

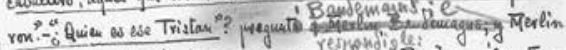

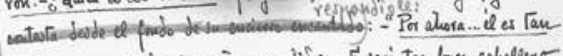

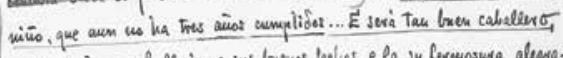

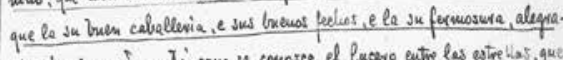

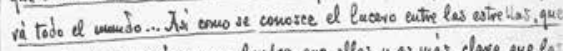

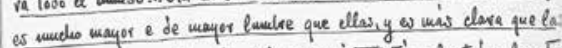

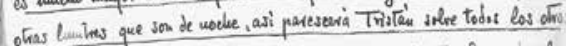

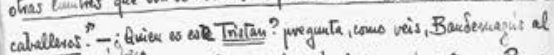

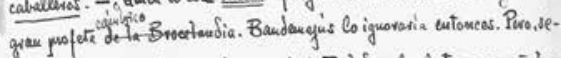
gurmeater que cuando se Fredyo aqui el Baladro, las lectores es wañoles 


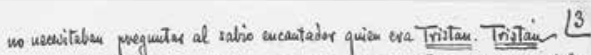

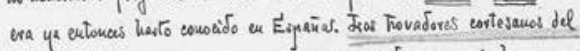
sigho XIT, los vaguates que congregatan ou toruo de su mesta juglares y can-

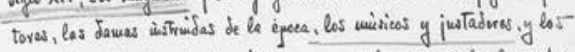

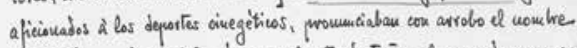

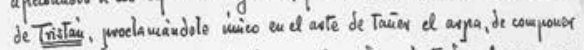

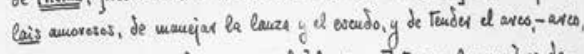

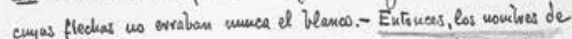

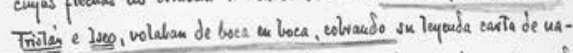

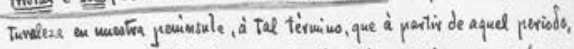

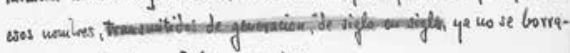
vin por medeo tian jos de las memovias.

Dos vias de transtrision in uerta, aute todo, señalar aqui: mua , litéravia, enudita, pateute on obras cuetas, novelas, poemas navratioos, can-

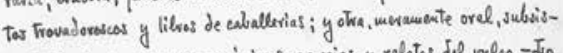

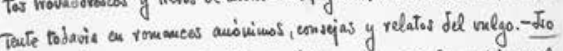

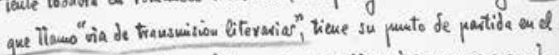

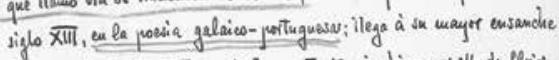

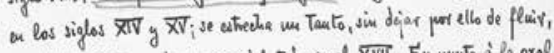

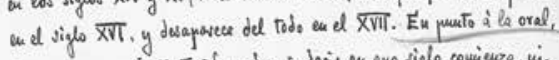

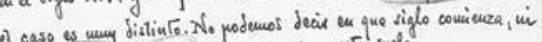

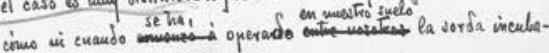

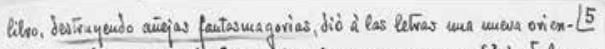

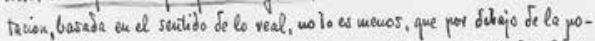
devosa ovitica cervautarer, y de sus burlas y parodias, por debajo del Quijo-

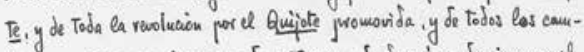
bios y rwolucioues literasias de cutouces, y de despeis, y de siempre, el

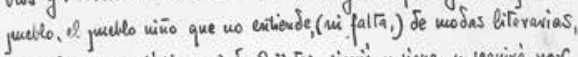
Se rtvoluciones astisticas, mi de Qüjolas, siguio, y sigue, y seguira jor

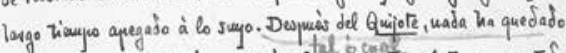

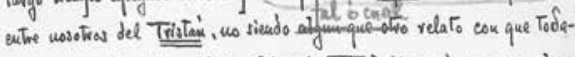
via los genealogistas ovedulos Sel siglo XVIT huliseron de exvinar algu-

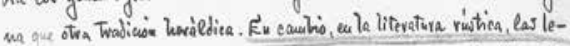

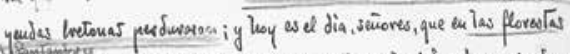

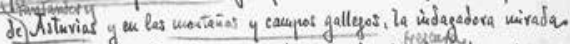

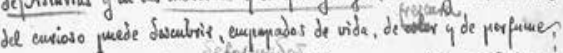

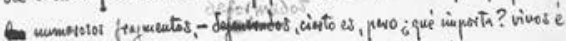

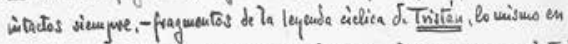

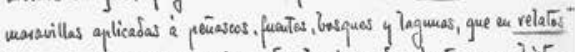
de hazaüas de valevowos raladines descalezadoras de monstricos, en histo-

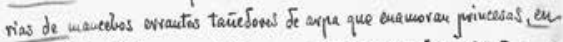

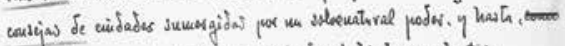

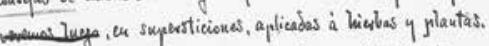

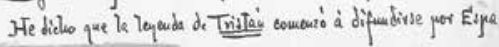

cion de was seniellas del cielo de Brotaüer; rolo saberwos, que la tradicion $L$

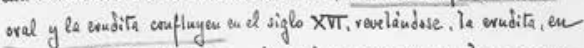
mulvas versiones noveleseas, $y$ la oral, en romaneas populares; y que mientias la wudita declina se ostarece y muere en el siglo XVII, la covriente oral sigue vimupre manando, viva y copiosar, en tal manevas, que

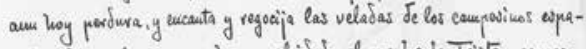

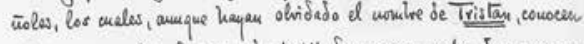
todaria, y mey à foudo, sus mas sigrificicadas proezas, sabeu de sus aven-

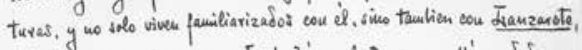

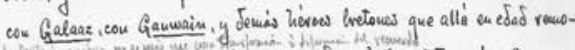
Ta companticion las glorias del emamorado caballevo. Yes más: Con ese.

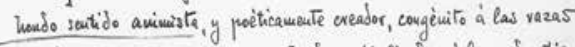

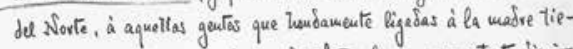
na viven en intima commenion con la Naturaleza y en contacto diario

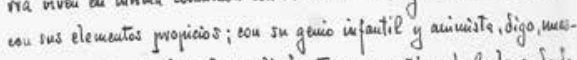
Tros campesinos del Norte hau aplicado Frozos y motivos de la leyerdade. Trivtain is su mitica rural, à memevosas Tradiciones locales i y eia es forwa en que actualuerite viven-algo onparanados, ciesto es, pevo con veal

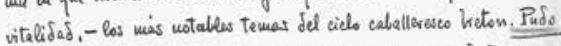
la siativa dioina de Cervastas logras que la liferatera cueta desterrasa jor siglas de su campo aquellos te mas cuajados de invemciones paregrives y

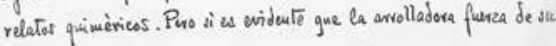

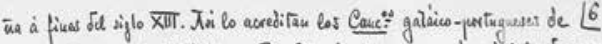

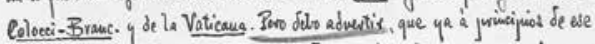

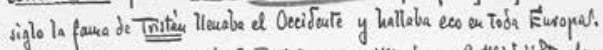

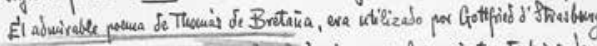

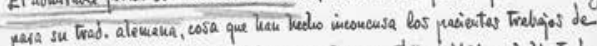

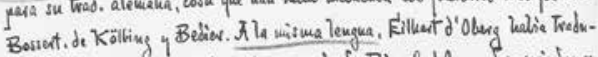
cido undwo autas el Tritain auflo-urmando de Bèroul, del que, dasgraciadamen

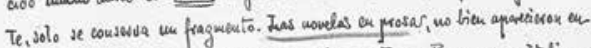

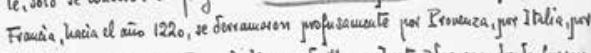

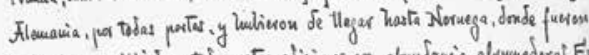

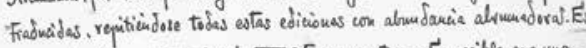
To ocunsia al promediar el siflo XIII. Y Y corte que era cuitoutes. vino la primena, por lo menas de las mas siguificadas y

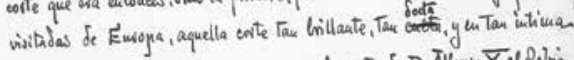

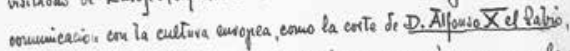

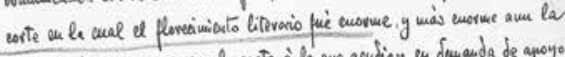

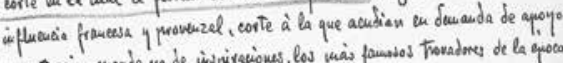

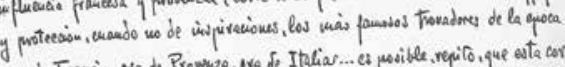

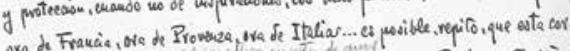

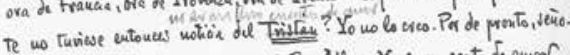

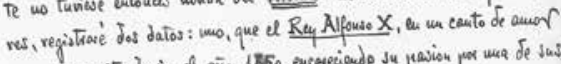

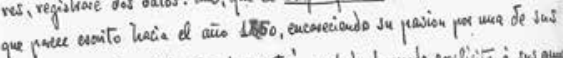

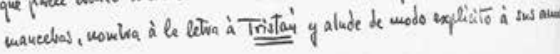




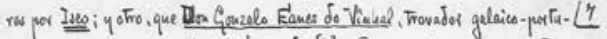

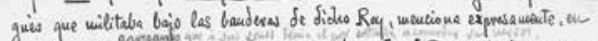
una de sus trovas, los lais de Cormoualle. Estos dos datos me bastarc, pues, y

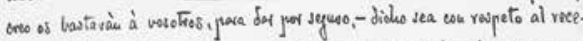

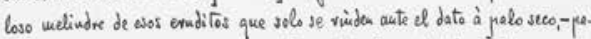

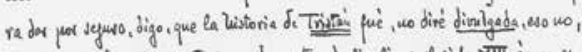

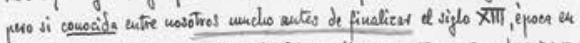

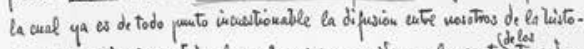

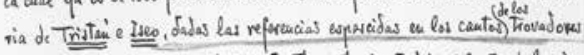

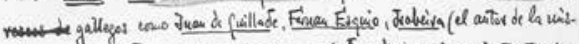

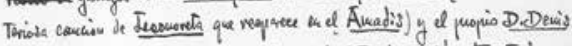

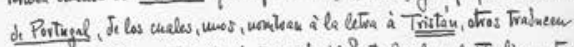

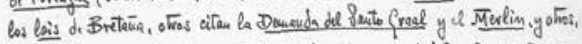

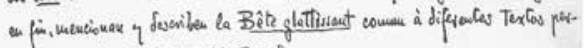
Tewirientas al cielo de la Tabla Rejonda.

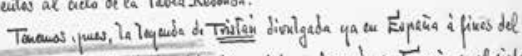

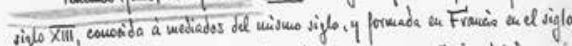

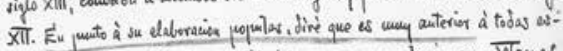

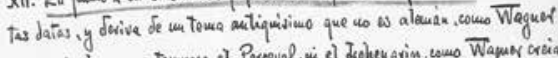

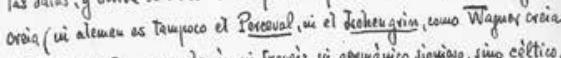

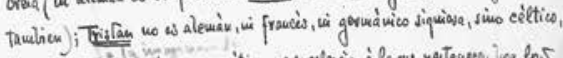

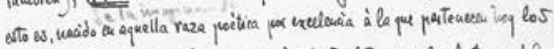
irelendeses, las gäels Se Estecia, los galor de Inglaterra y los hetoues del

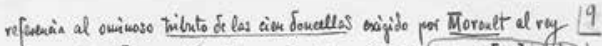

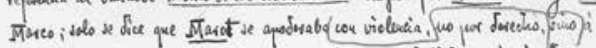

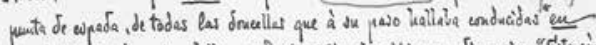

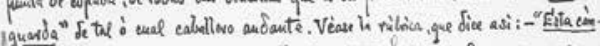
tigs-digo ouitiga... - fereser quatro Jonzeles à Manot d' Trlande en tewpo de

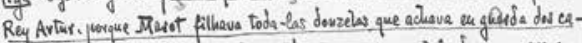

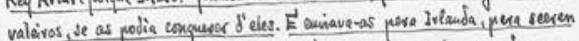

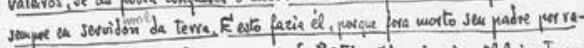

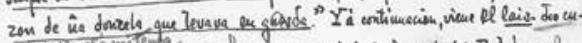

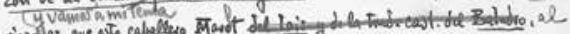

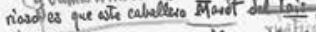

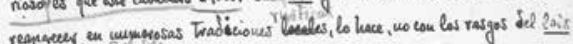

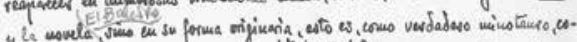

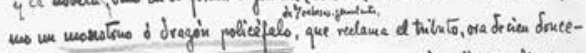

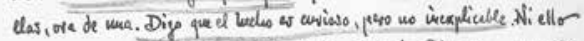

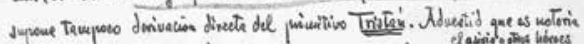

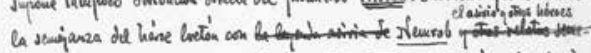

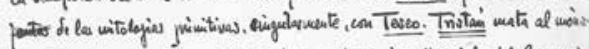

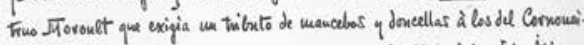

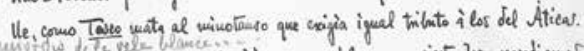

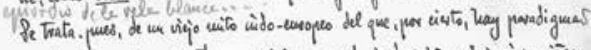

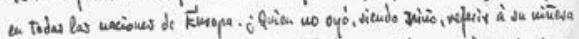

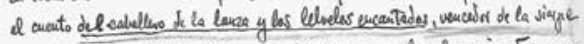

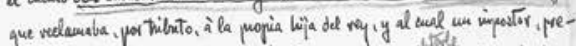

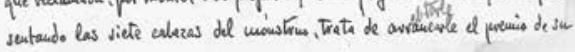

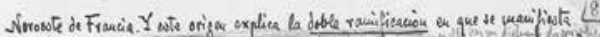

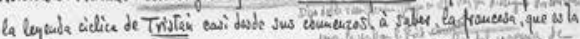

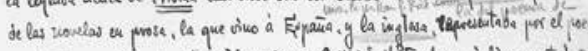

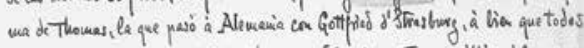

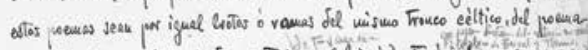

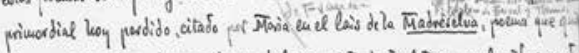

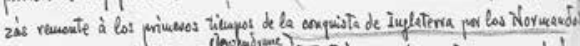

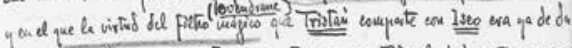

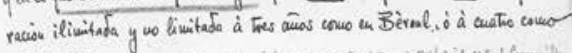

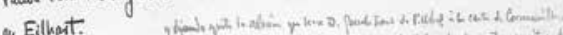

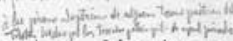

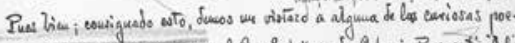

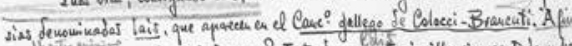

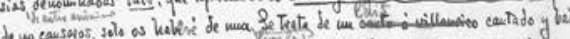

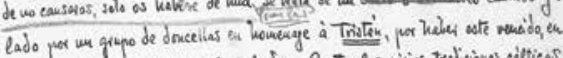

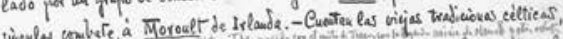

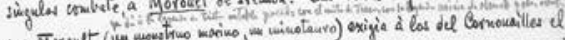

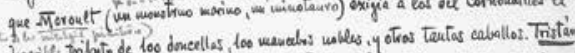

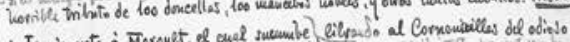

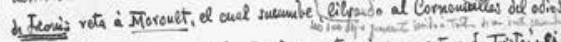

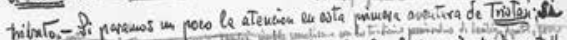

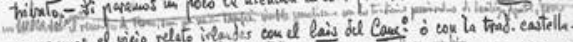

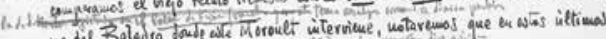

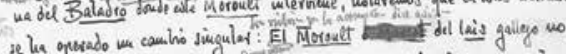

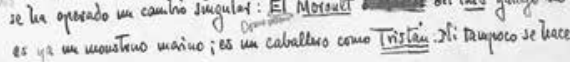

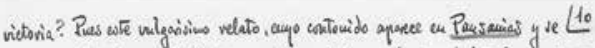

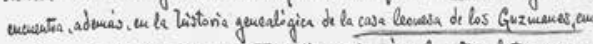

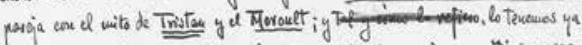

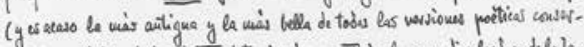

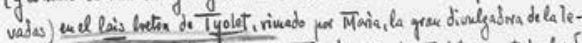

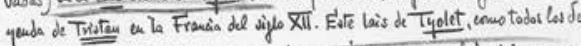

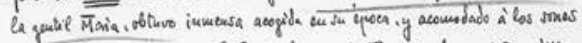

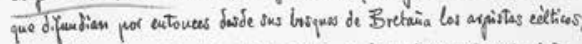

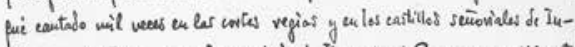

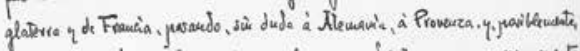

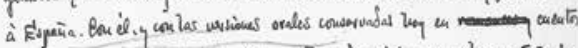

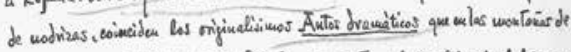

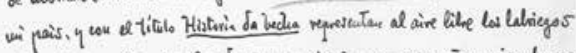

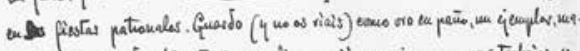

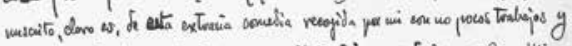

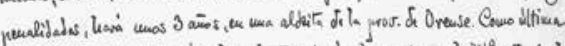

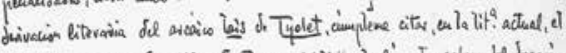

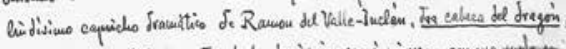

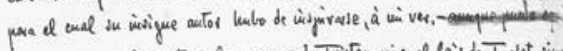

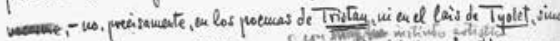

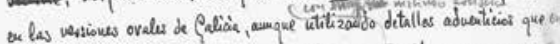

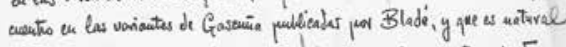

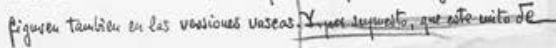




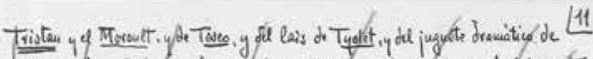

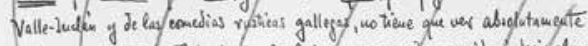

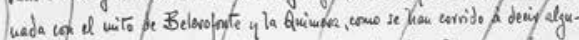

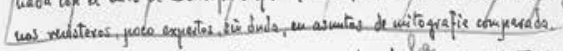

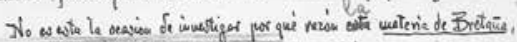

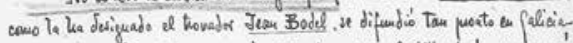

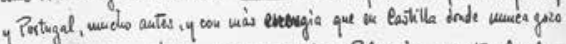

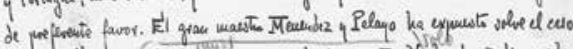

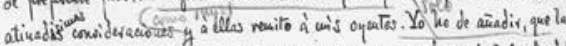

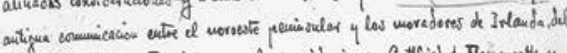

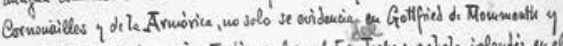

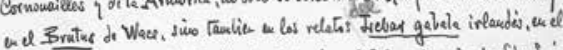

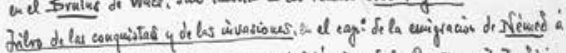

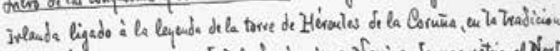

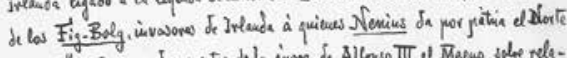

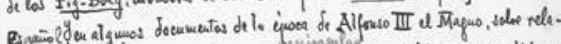

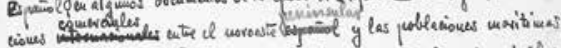

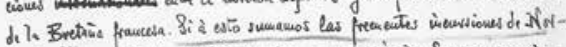

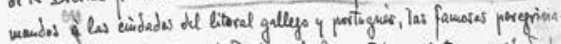

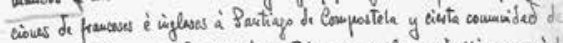

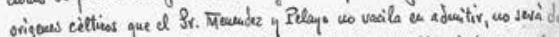

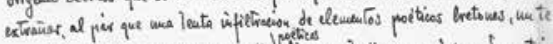

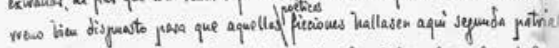

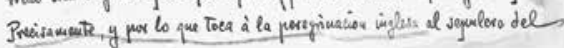

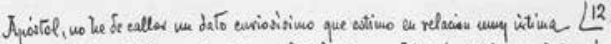

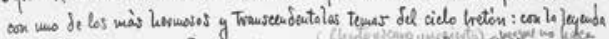

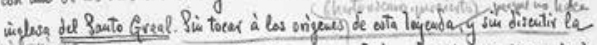

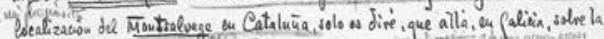

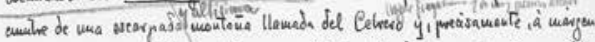

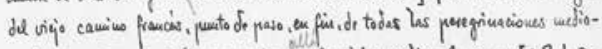

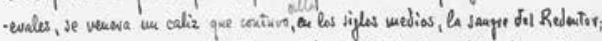

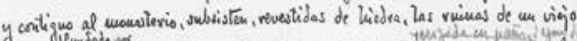

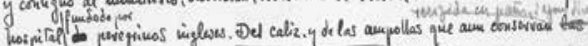

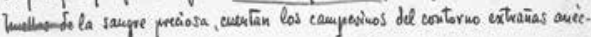

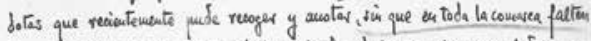

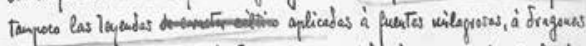

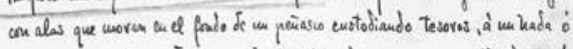

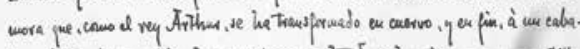

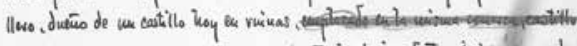

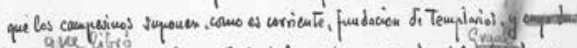

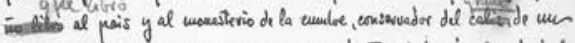

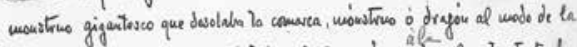

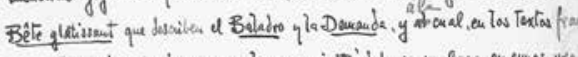

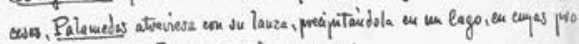
fundidades se humate con antruendo pavovose?

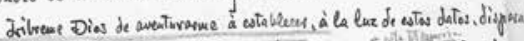

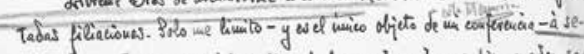

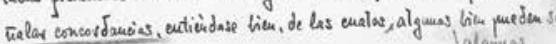

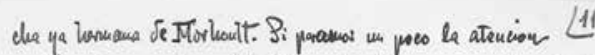
jee asta mimeve aneritura d. Tristan, la cual no woes volamente el

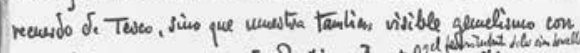

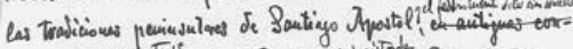

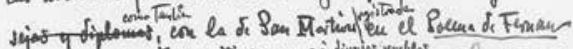

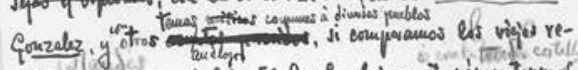

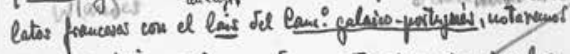

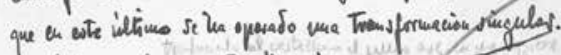

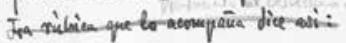

"Este lais.

Jmpintyouth

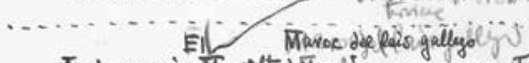

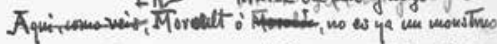

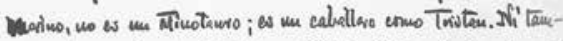
yo se hace vofereria al titimaso thilnto Je las cien donalles exai

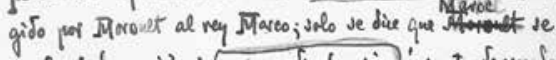

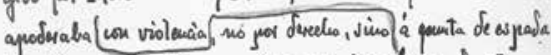
de todas las doneellas que à su paso hell dia condunides en

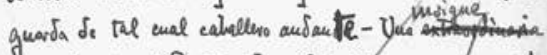

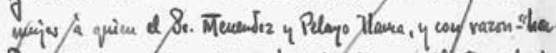

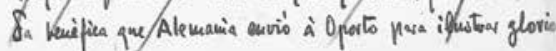

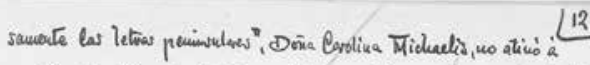

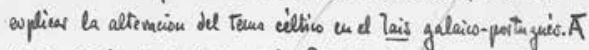
juicio mio, la decovientation de la Sra Midenelis proviesce de uo

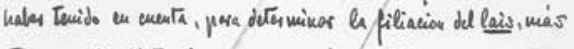

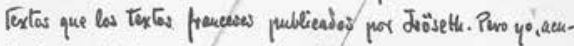

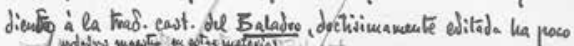

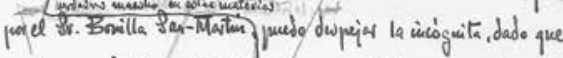
aqui aprasee la figura de M̄ornult comespondicidose ene un Todo conk del lais gelaico-postuguis, reforzaidose con ello la quivion de que wite

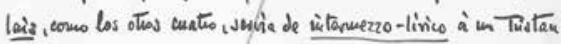
on prose, empo Twe diferia ya de los pranceses que Rey subsiatere y del

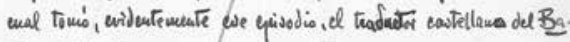
ladeo. El thrto de la monela castelleun dice asi :

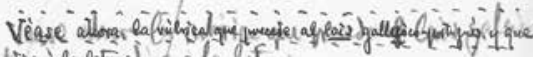

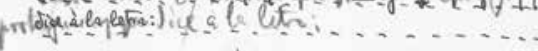

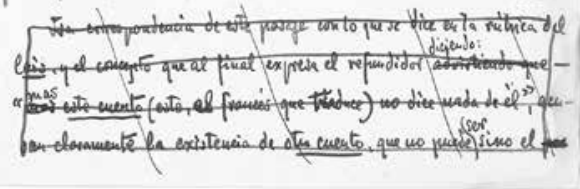




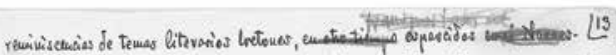

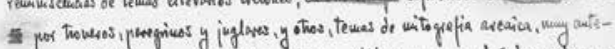

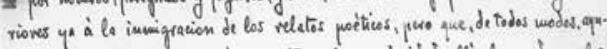

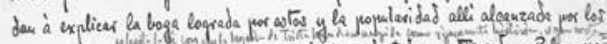

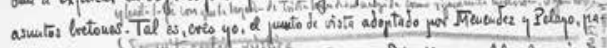

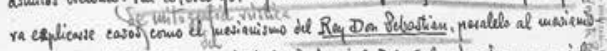

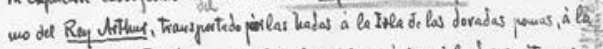

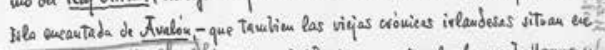

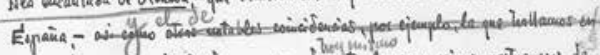

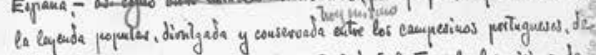

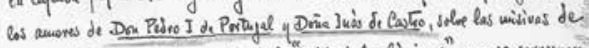

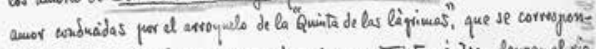

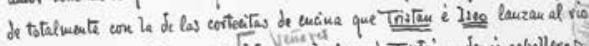

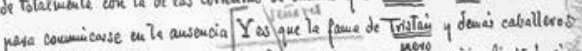

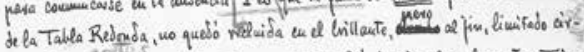

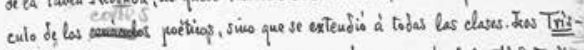

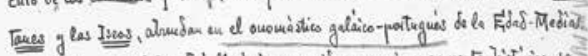

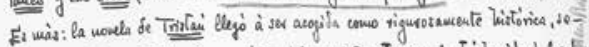

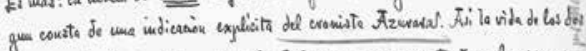

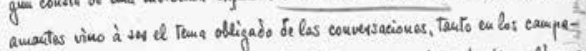

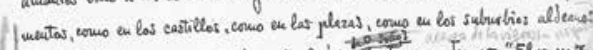

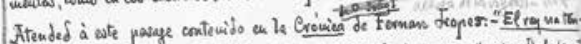

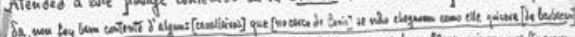

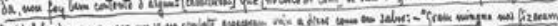

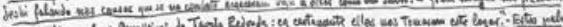

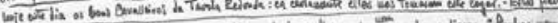

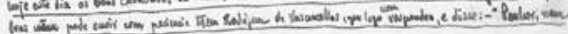

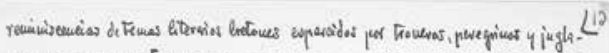

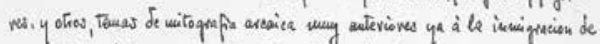

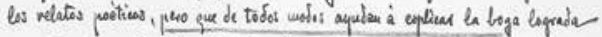

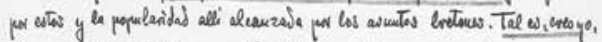

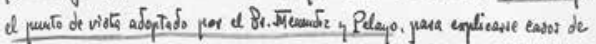

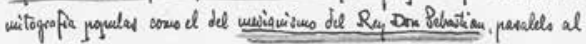

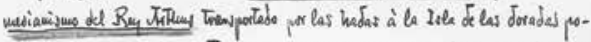

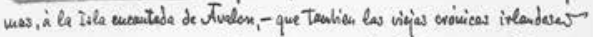

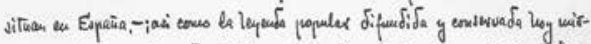

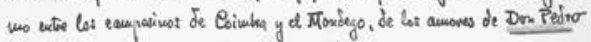

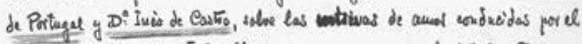

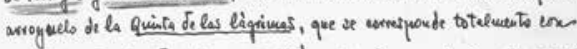

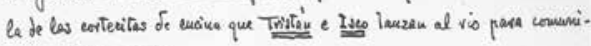
exse ex la ansonciat.

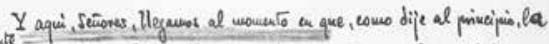

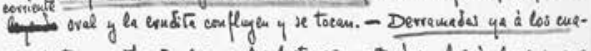

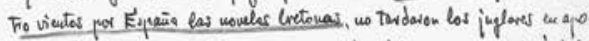

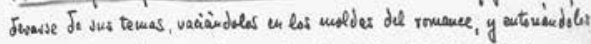

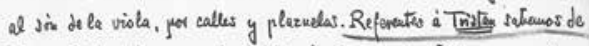

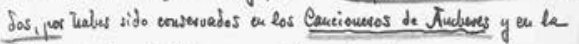
Colececian de Juan de Rivera, neno de los cuales, dice asi:

"Fuido esti D. Tristai - de mea mela lancads

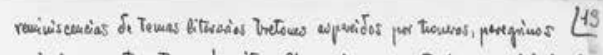

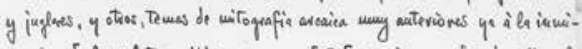

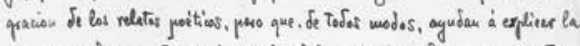
boga lograda par estos y la populavidad aqui alemarada jor los relatos

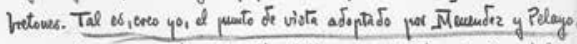

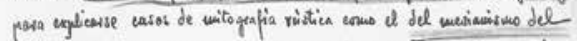

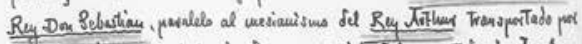

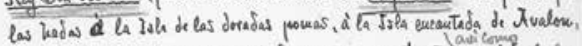

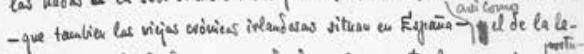

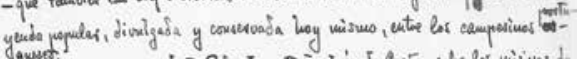

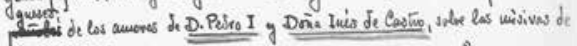

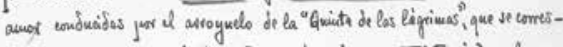

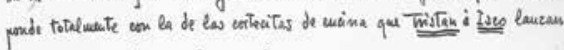

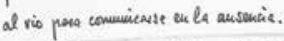

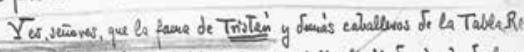

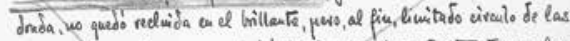

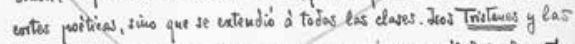

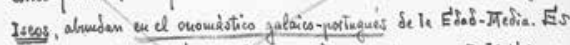

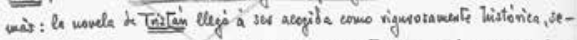

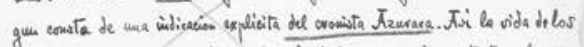

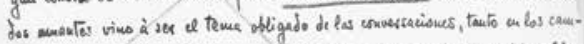

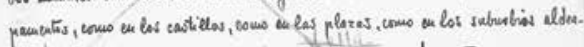

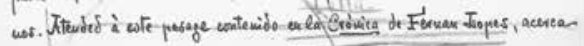

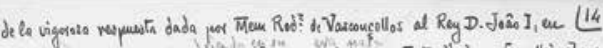

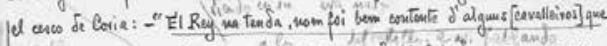

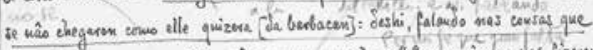

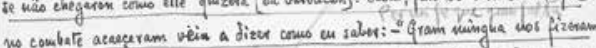

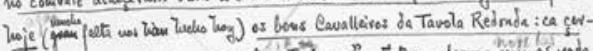

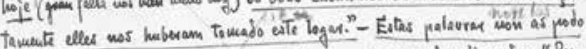

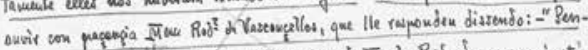

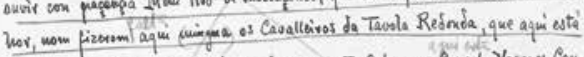

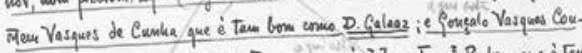

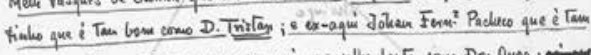

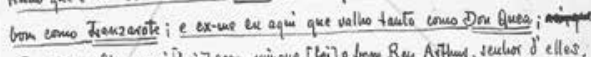

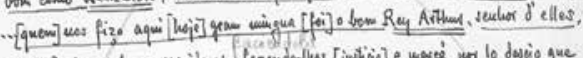

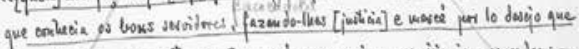

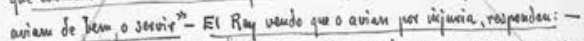

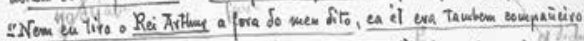

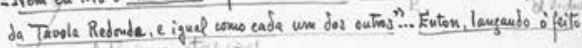

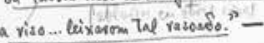

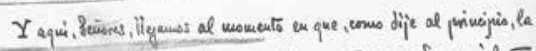
corrieste oral y la endita conflengen y se Tocan - Derramadas ya à los

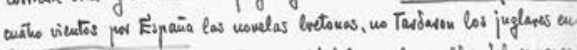

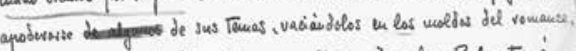

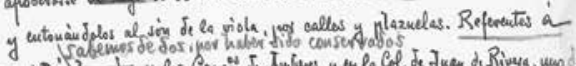

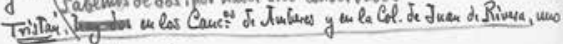
los cuales, dice asi: 


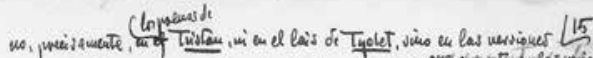

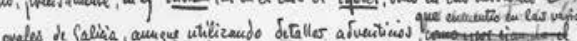

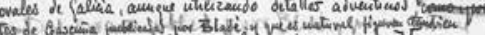

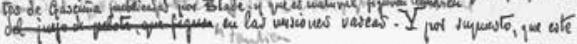

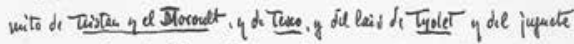

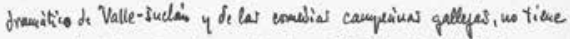

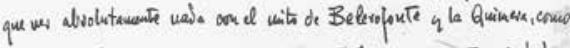

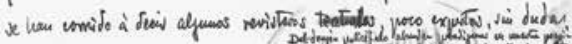

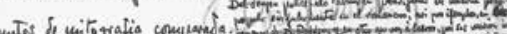

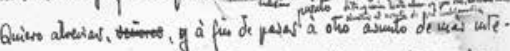

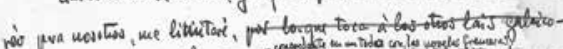

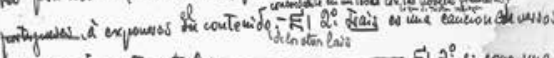

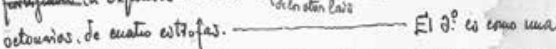

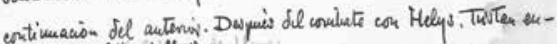

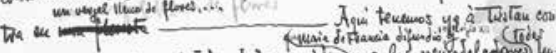

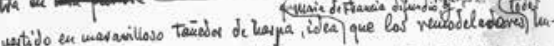

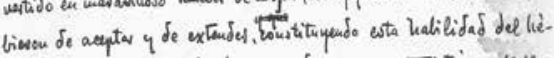

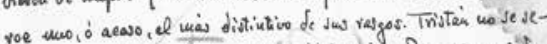

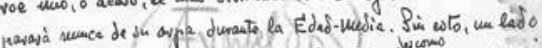

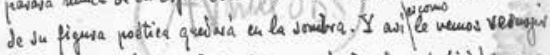
en el cuarto y ietrive de los lais, cuando kenido y habicindose eqpoJurado There de le Joyna-Grasda, eamine de wocke

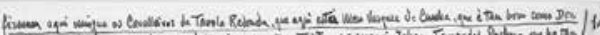

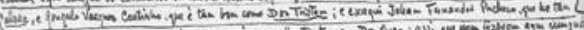
Der

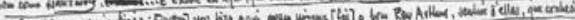

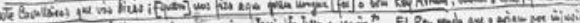

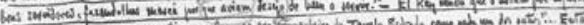

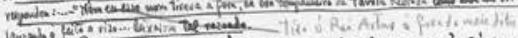

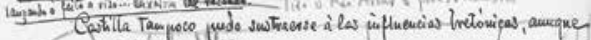

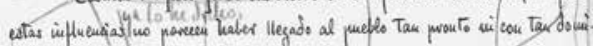

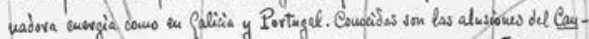

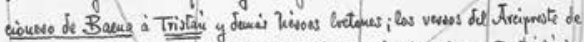

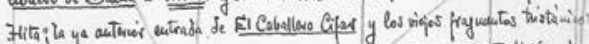

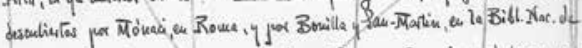

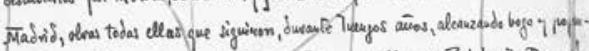

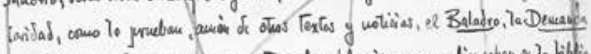

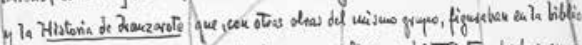

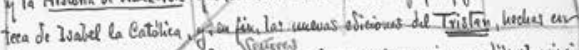

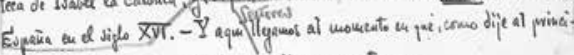

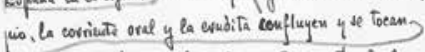

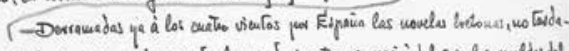

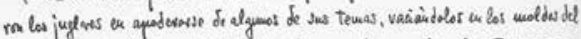

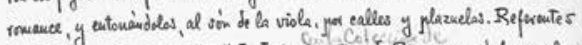

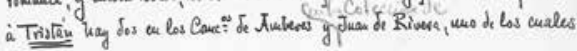
die asi:

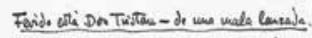

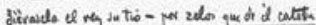

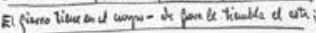

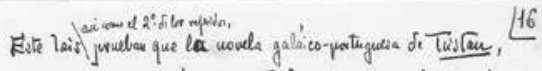

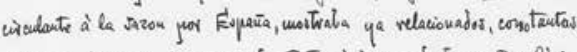
versiones frencesas, los Theras de Tastan i treo y de tranzenote y fice -

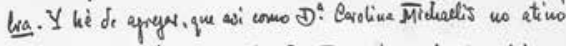
à explicarse la trawjormanon del Mrovoult en el primes Lais ga-

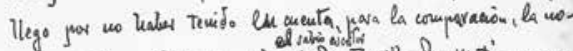
vela castellawar, de igual modo, \&t fr. Brailla Pau-Wuatin, por wo

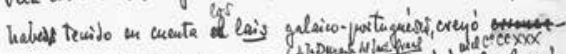
te que el treductor castellenar hatie confundido la leyanda Se Ienzarefe y fincles con le de Thiten i Jise, araido lo gue ha

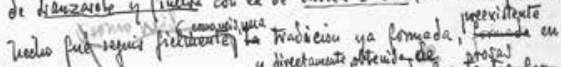

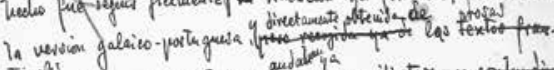

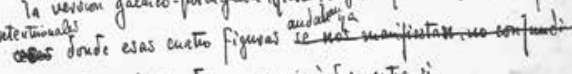

relacionadas y comancicandose entre si.

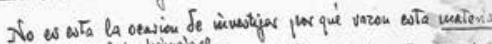

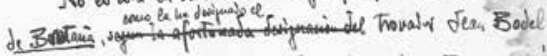

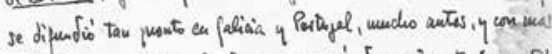

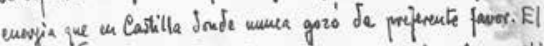
gram menerive y Pelayo ka expento solve el caso ati-

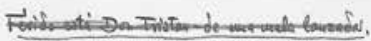

dietrasela el vey su tio - por zelos que dél cataia.

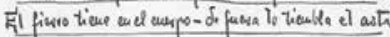
Valo a ver to Reina dseo - por le de dudieha vala. Jintanse bece con breca - enanto mus misa vizadas. Slova ol mos, llove de otro, - la cama baĩan en aguas. Jili race un arboledo - que azsoctue se llamaba. Cualquior unjer que lo come-luego [queda evilosazada]

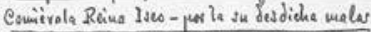

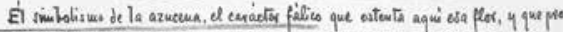

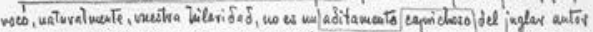

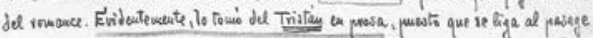

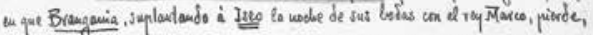

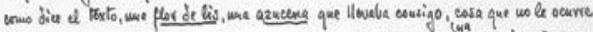

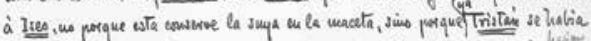

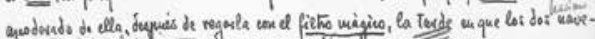

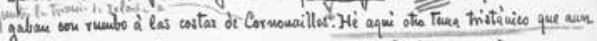

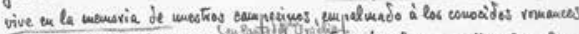

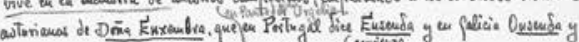

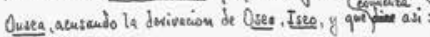

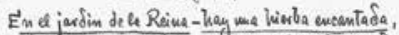
Todg mujer que la ción - lueso queda culbarazados.

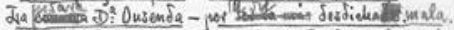

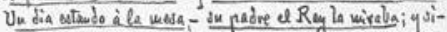

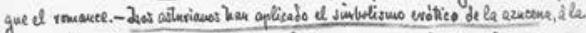

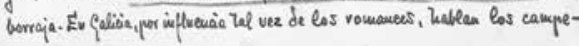




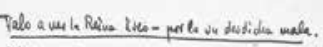

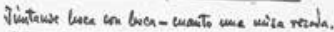

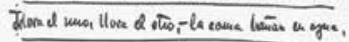

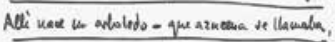

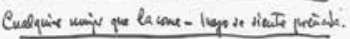

Conièmle reina jues- jow la to dutides mala.

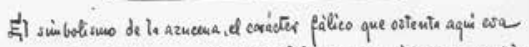

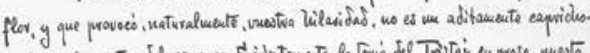

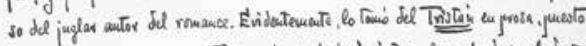

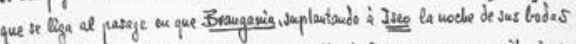

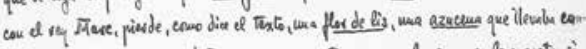

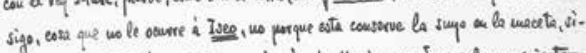

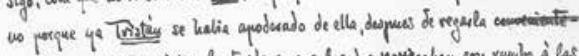

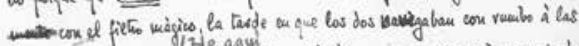

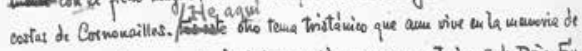

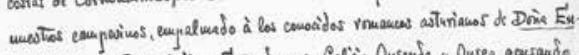

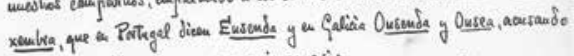
Ia decivacion Oseo, iseo, y que conimenza asi:

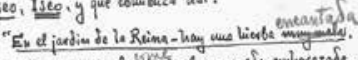

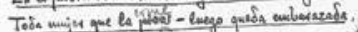

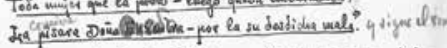

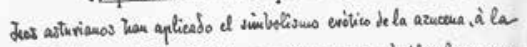

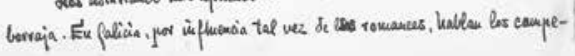

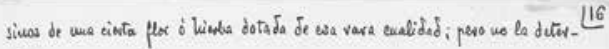
swiven.

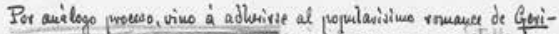

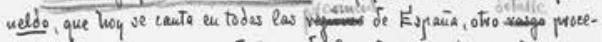

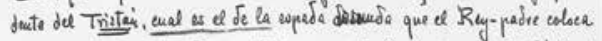

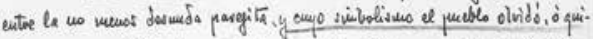

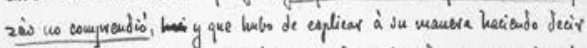

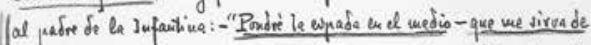

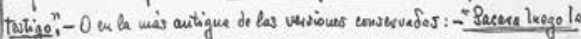

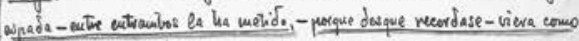

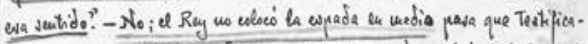

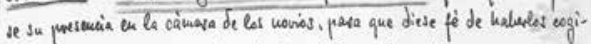

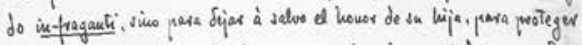

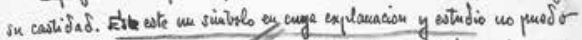

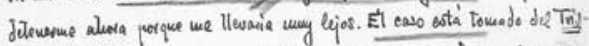

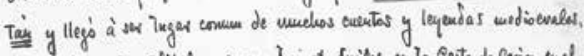

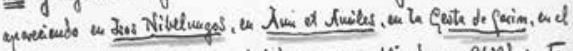

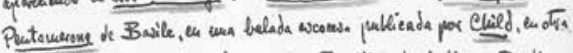

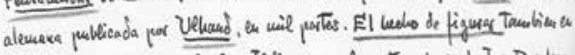

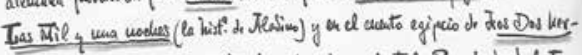

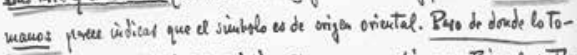

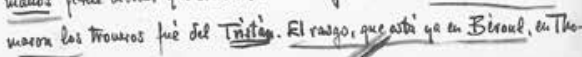

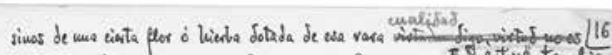

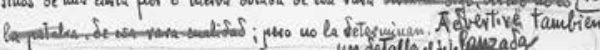

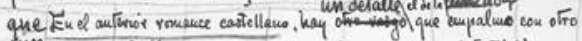

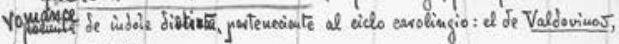
cuma eutrada dice:

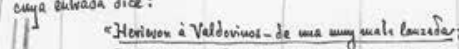

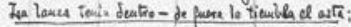

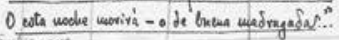

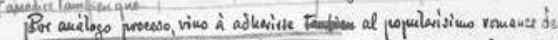

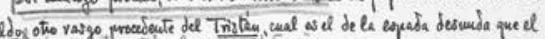

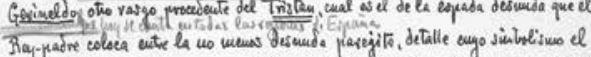

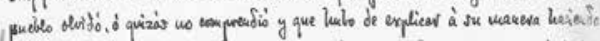

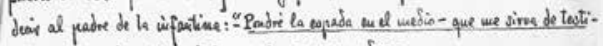

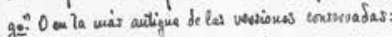

"Paeare laye la wrades-entre cutroulos la ha witido.

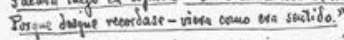

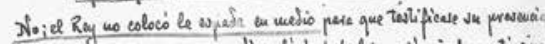

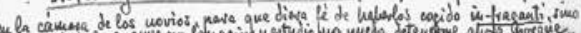

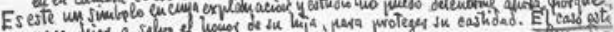

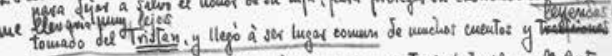

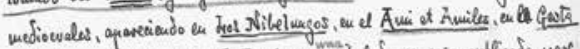

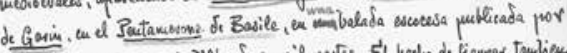

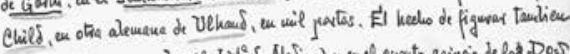

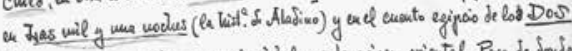
Hermanas, jerrece tidicas que el simbole es de origar oriental. Puso de donde

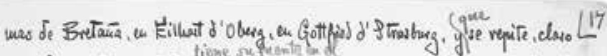

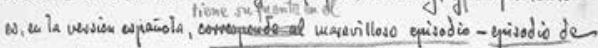

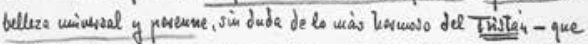

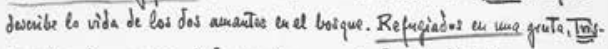

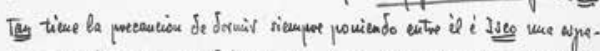

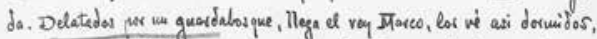

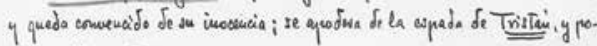
ue en su lugar la Juyas.

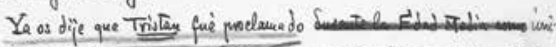

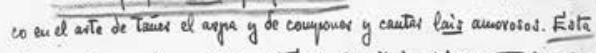

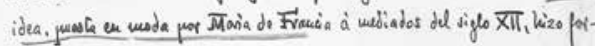

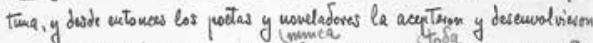

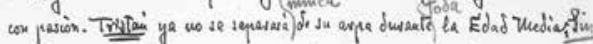

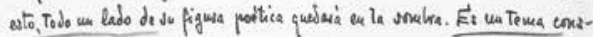

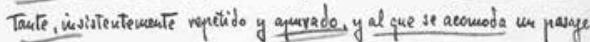

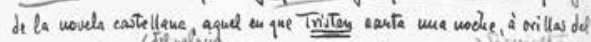

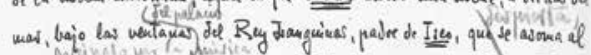

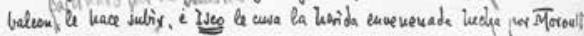

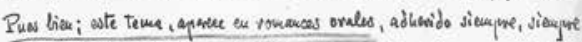

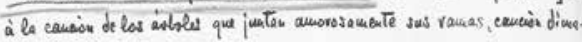
unda, cou Toda evideriá, Sel Tristaì. De aste motivo de los ishress, que wtá 


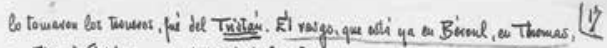

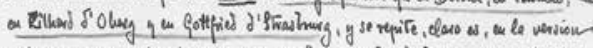

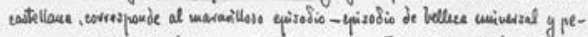

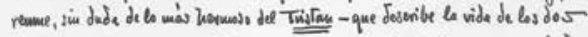

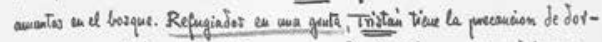

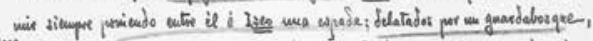

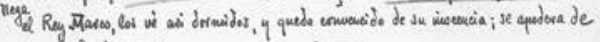

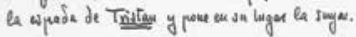

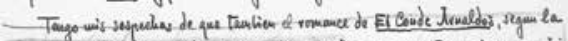

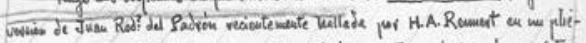

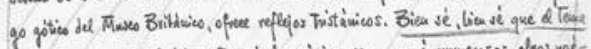

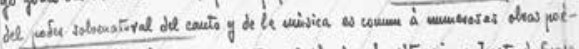

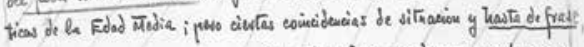

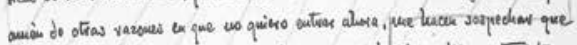

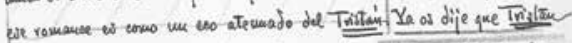

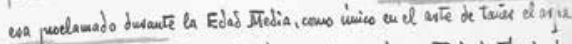

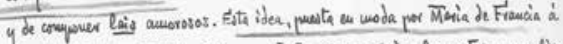

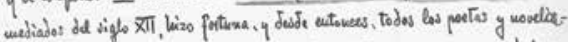

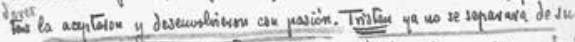

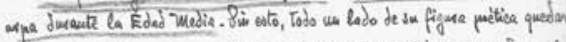

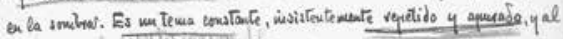

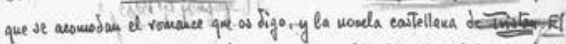
quanew aquel an que Thistai santa una noche, à orillas del mar, bajo las vertanas del Ray Jam grivess, padre de Iseo, que ser as muas al bal-

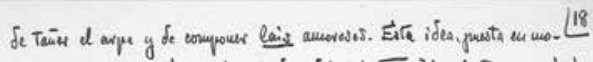

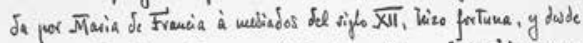

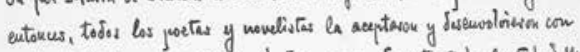

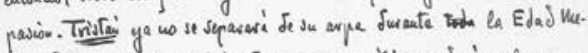

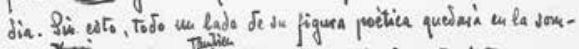

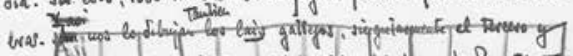

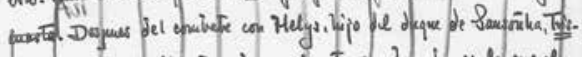

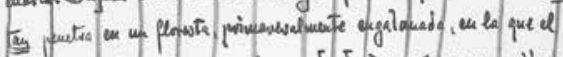

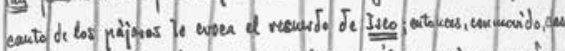

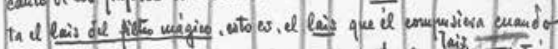

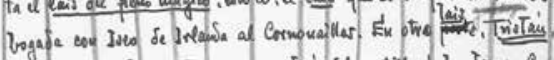

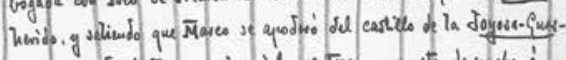

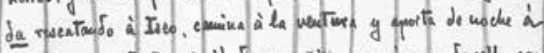

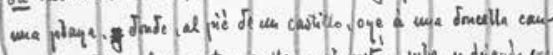

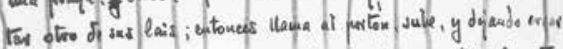

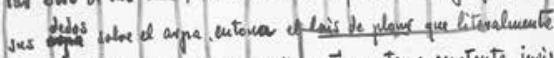

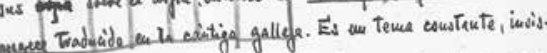

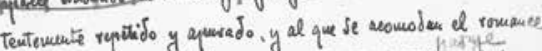

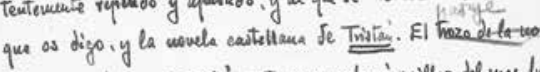
veta os aquel en que Thistai centa una noduc, a orilles del mes, bajo

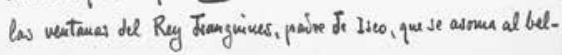

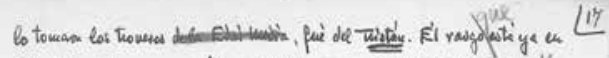

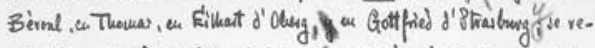

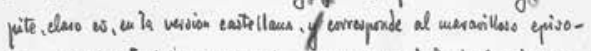

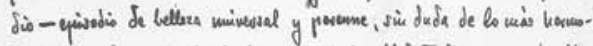

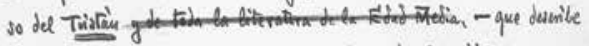

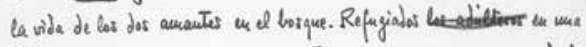

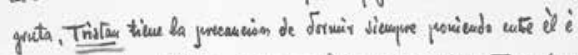

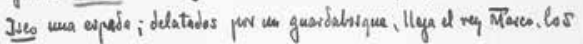

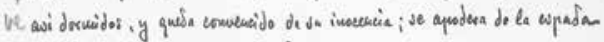
de Tristan y rouse ensu lugas le suega.

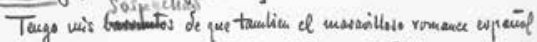

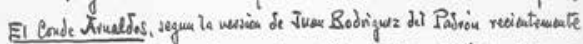

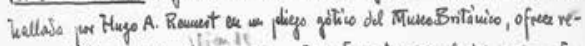

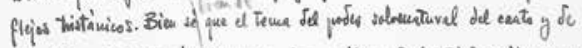

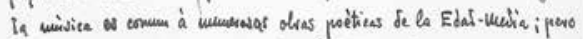

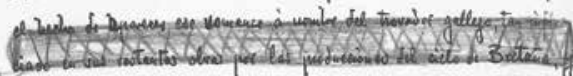

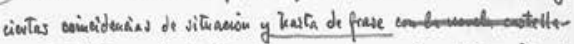

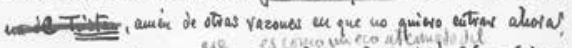

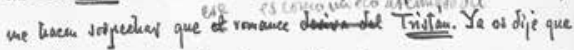

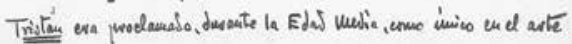

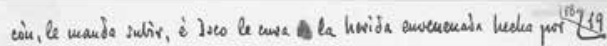

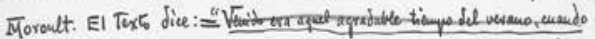

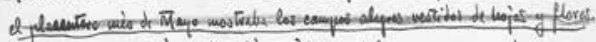

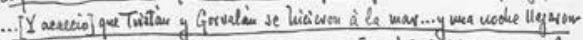

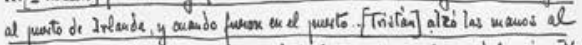

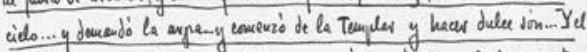

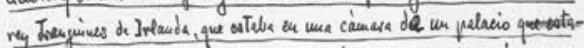

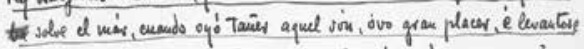

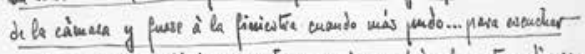

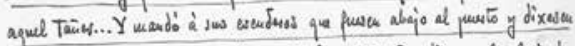

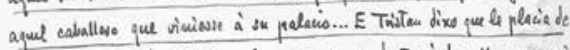

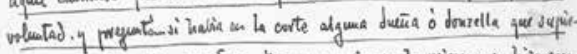

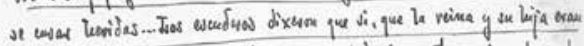

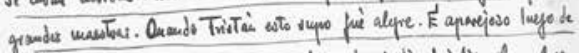

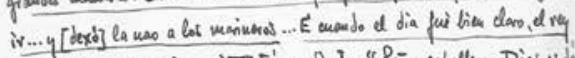

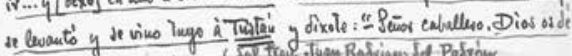

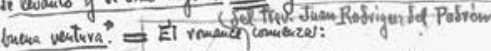

$$
\begin{aligned}
& \text { Qnia Turiese atel ventura - en ins anores folgre }
\end{aligned}
$$

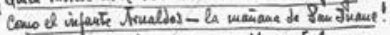

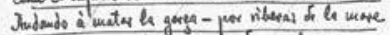

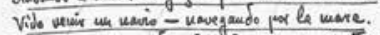

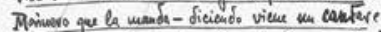

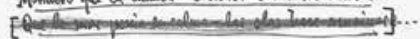

Mis adilante, epryes: 


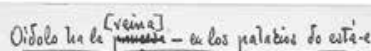

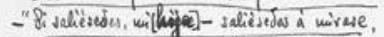

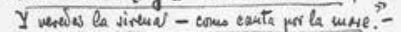

- "ine non era la sirena - la sirena de la mase.

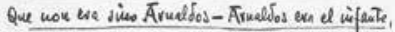

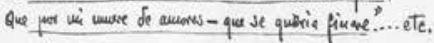

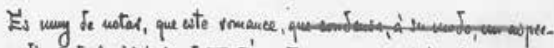

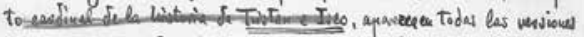

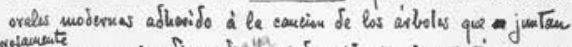

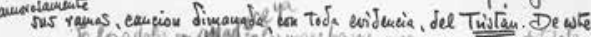

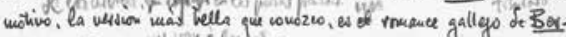

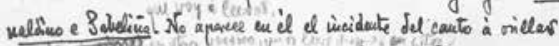

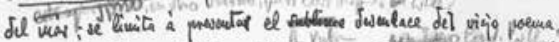

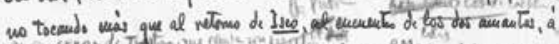

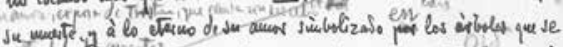

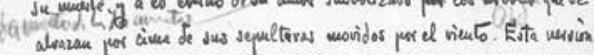

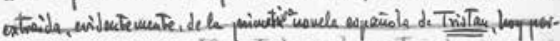

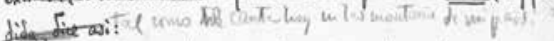

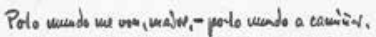

En misea.

Torow -

- De Butual
- Brenclitio

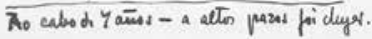

Polodia, po-la wite - 'no xadin witè à cautari:-

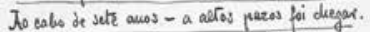

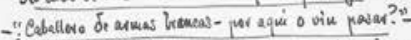

- Cabelleso de ankas Wraneas -'no men monte vai cazer.

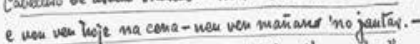

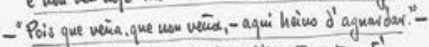

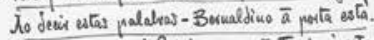

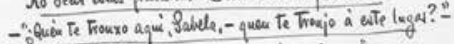

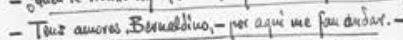

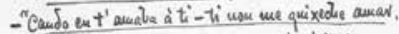

Jgora son da Reiru - e nou a podo derias:

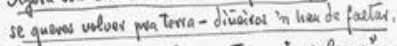

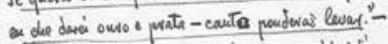

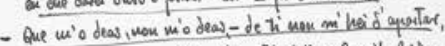

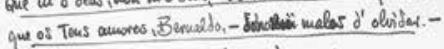
Collivanse po-10 hazo, - puxiesonse à rasear.

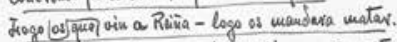

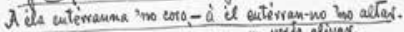

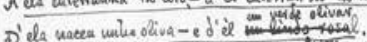

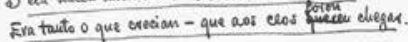

Cendo os verites................ -

Cando os wortas

Joge que or vin a Reiñe — evitar

D'ela necen wike forte

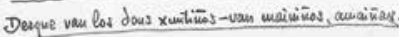

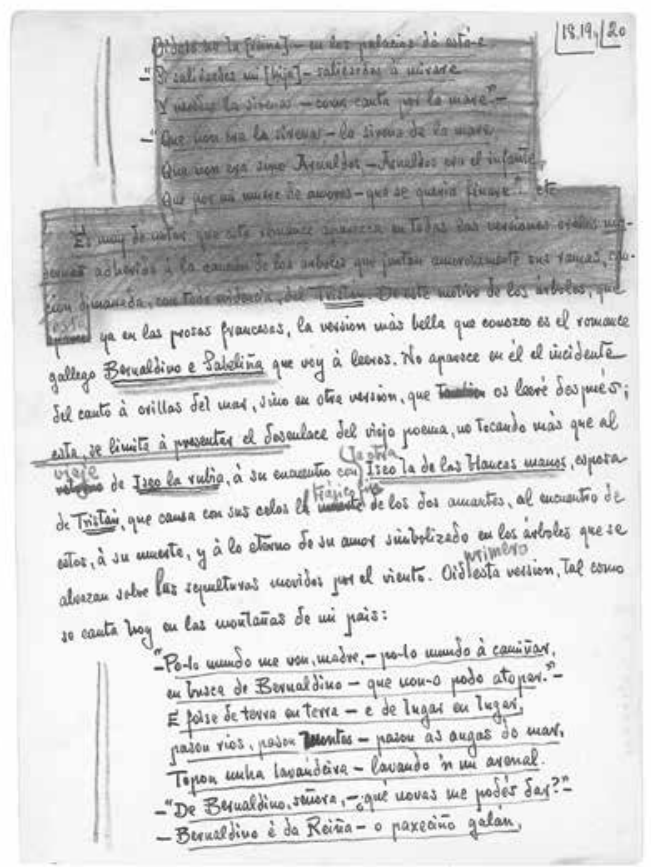

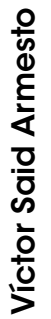

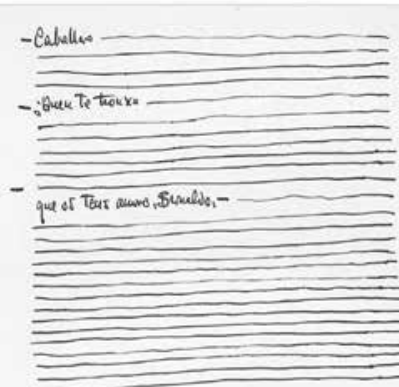

$\lfloor 21$

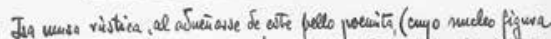

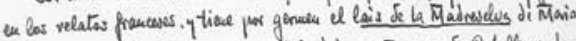

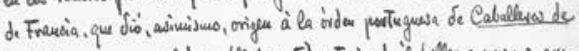

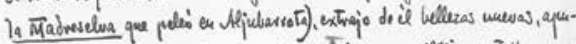

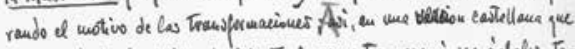

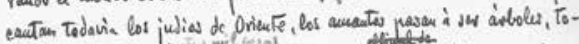

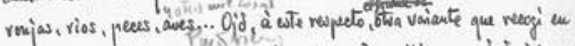

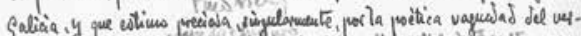

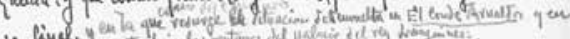

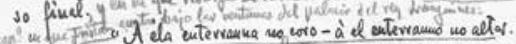
De de racest unca fota - e de il un lossciro veal. Teuto creeter un $y-0$ outho-que se form a xuntor. A Reitue var pva uita - e al' preudese o sayal A Reiña de envidiosa - loge cuandounos cortars, 


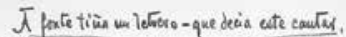

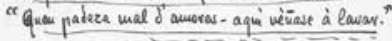

$$
\text { . }
$$

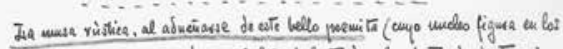

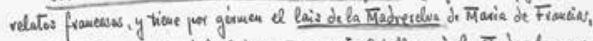

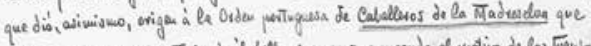

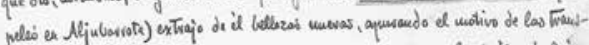

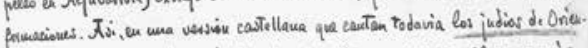

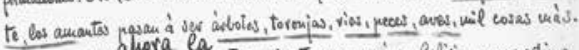
Pes aliora la ba Puestion; oid.

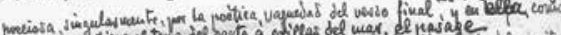

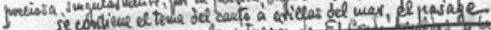

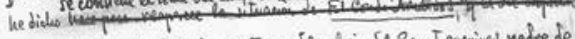

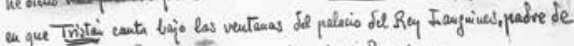

Iseo: Camálabs Cardegivo - mainagada de Pan Xuan

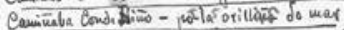

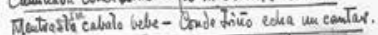

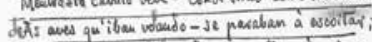
LOS neeses qui iban ino fondo - se salian à mivar;

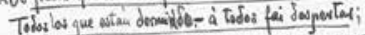

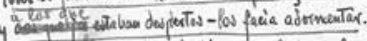

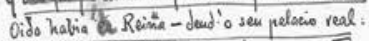

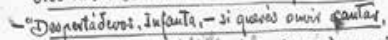

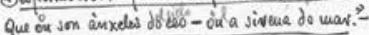

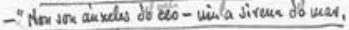

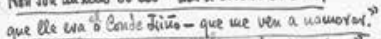

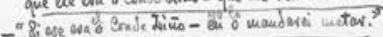

Ëla vitar liste clasa - èl verter saumper veal. de ela necten una forit - e de el cur luido arroy al Ele tento o que cortian - que se from à xurtas. A Reiña vai pra wise-os pies iboulle a molles.

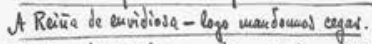
Ela ve volven peloure - y el un lindo gavilin Tanto vean un y-o ontro - que aos cees querou clayers, Voabias ala cou ale - pra vos ceos J'aluazas, Vastian bito con trico - pra mos reas se tiees, E Tanto e taulo voason - que ve perdurn no ar....

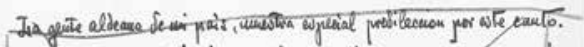

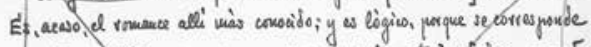

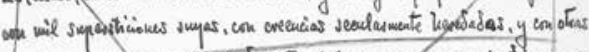

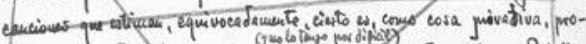

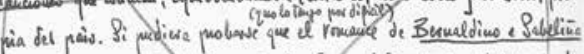

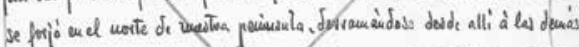

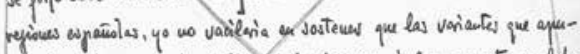

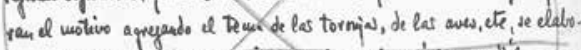

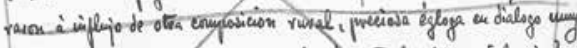

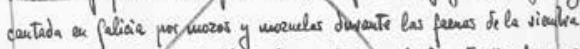

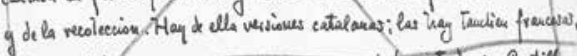

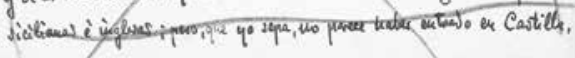

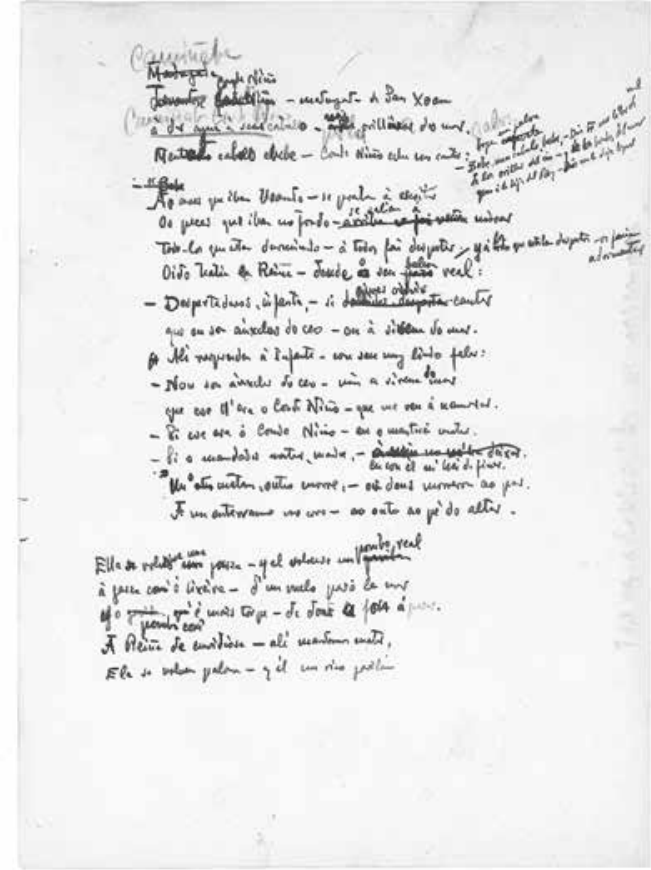

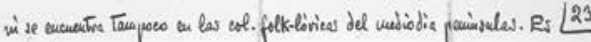
conos digue:

- Apui vecio Rosa, - Rocinara rezada,

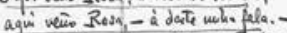

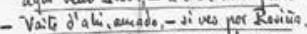

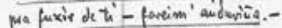

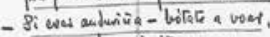
swei cazado - inetre a cazas. -

- Vaile d'alis amajo, - jiares cazador. ma puxis de $\vec{k}$ - parime whe flor. -

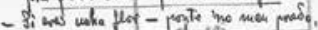

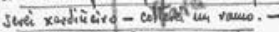

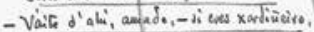

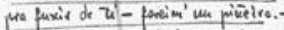

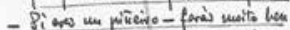

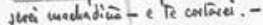

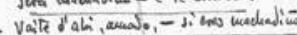

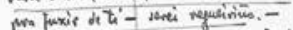

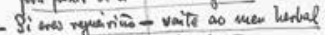

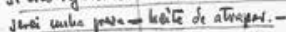

- vaite d'ali ameado - ji wess malla presa

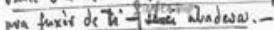

- Si wer abadeva - vaife pio comoluto.

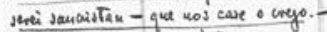

- Bi nos cara i arejo - verte, mer anijo. vinte, were arado, - casari contigo. -

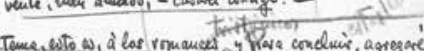

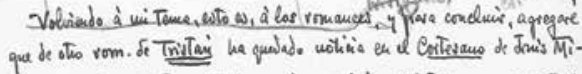

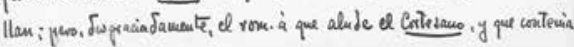


If fio mandados matar, madre,-ercon ie hai de fines?

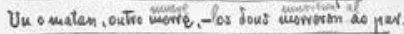

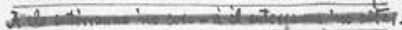

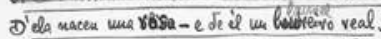

Tauto coreth the yo sutros - que se forion a xuitar.

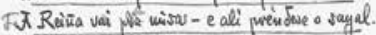

LA Reiña de colosa-logo mandonuos cortan.

Ela wister leite clava - el wateu samere real.

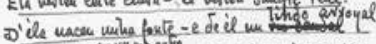

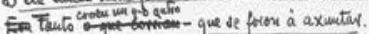

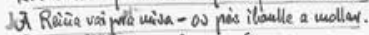

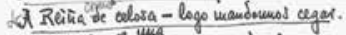

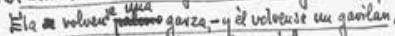

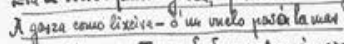

y o gavilan enuor Tone- Se doust a fora à pasar.

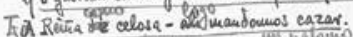

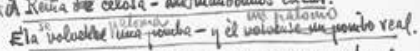

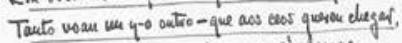

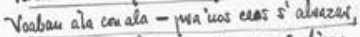

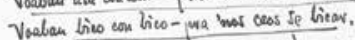

Etrato e tants voavon - que se perdecon no ar...

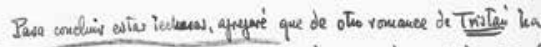

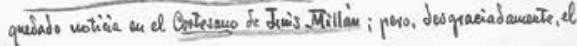
romarce à que alude el Cortesano, que conteria el verso

"que por weres, ini suiora-pase yo le war saleda."

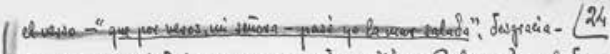

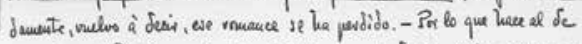

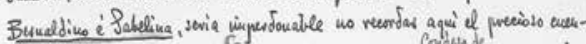

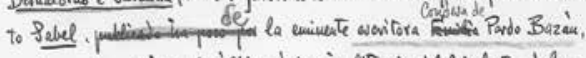

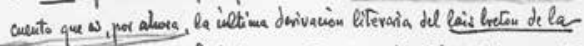

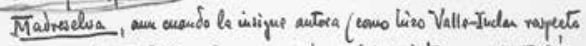

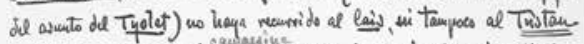

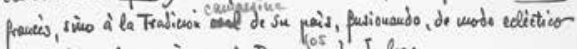

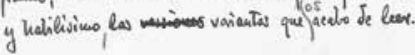

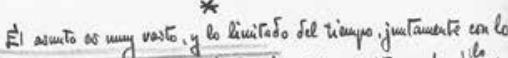

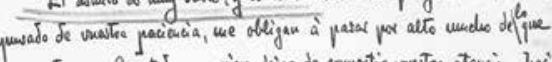

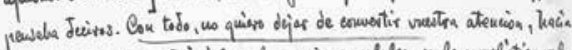

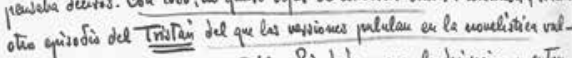

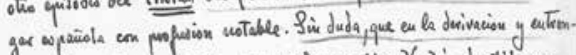

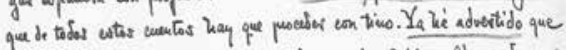

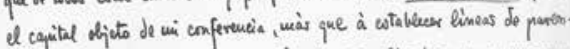
Terro, se onceamina à señalar concordancias. De ellas kay ma der mercuen-

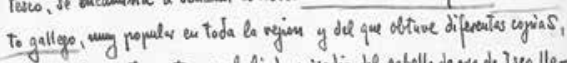
que coincide unactemente con el lindo crisodio del cabello de oro de lsce lle-

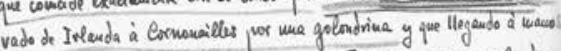

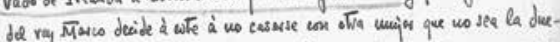

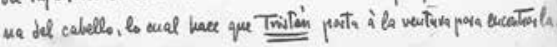

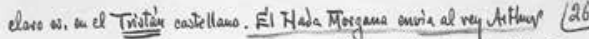

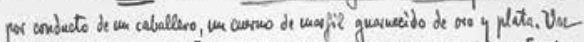

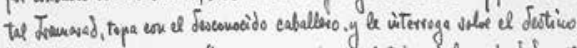

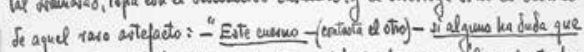

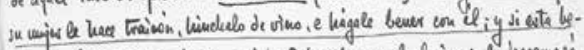

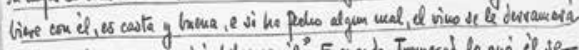

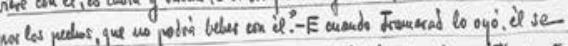

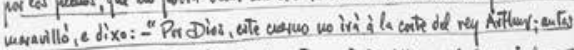

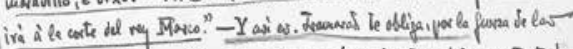

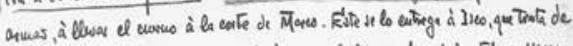

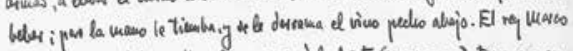

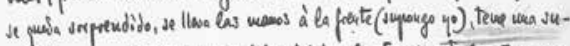

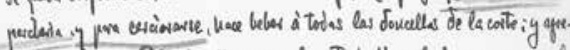

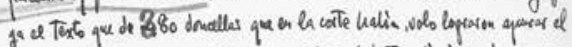

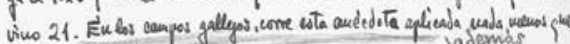

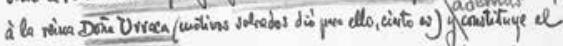

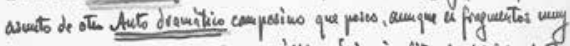

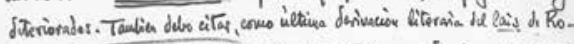

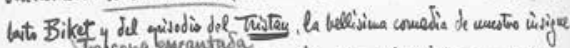

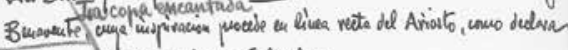

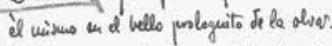

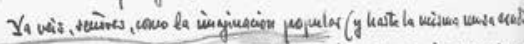

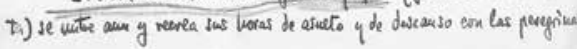

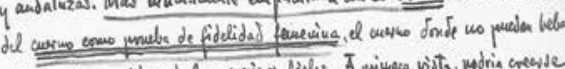

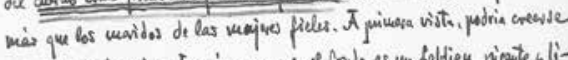

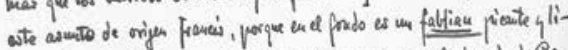

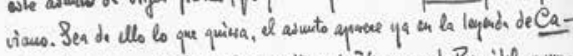

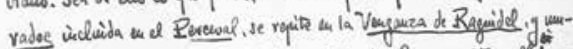

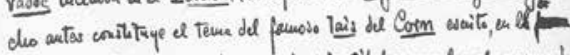

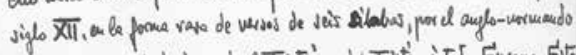

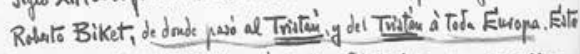

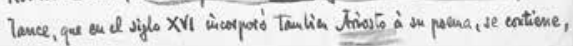




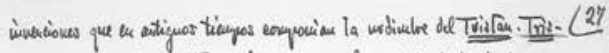

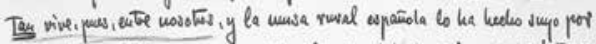

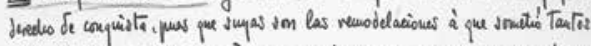

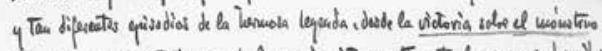

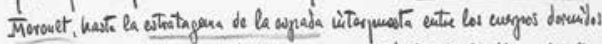

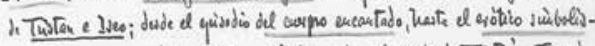

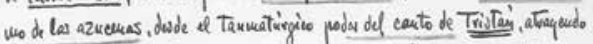

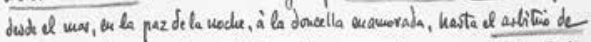

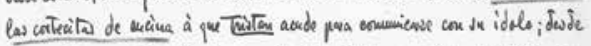

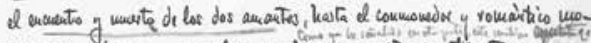

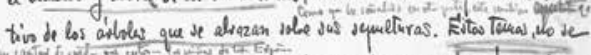

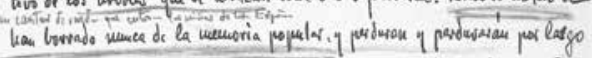

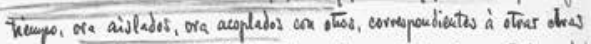

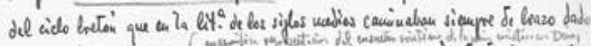

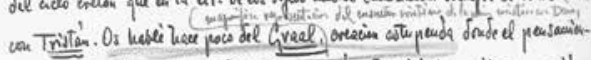

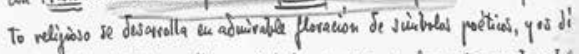

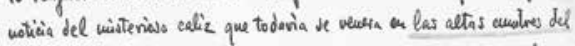

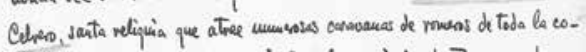

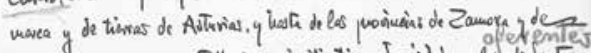

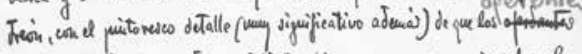

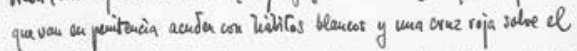

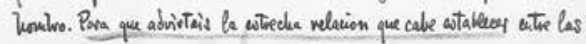
ristar

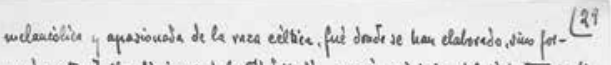

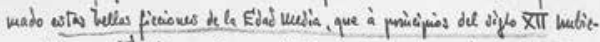

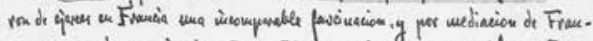

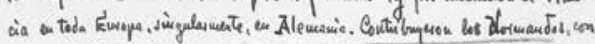

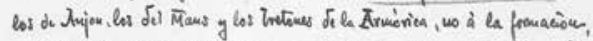

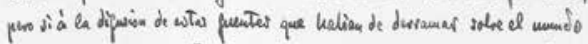

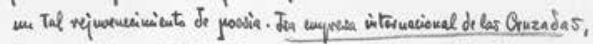

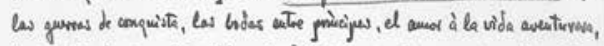

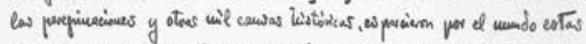

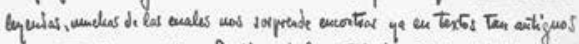

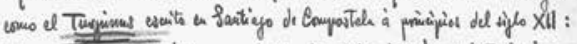

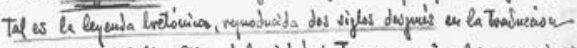

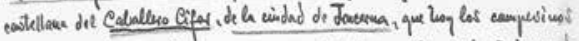

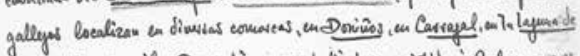

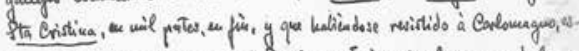

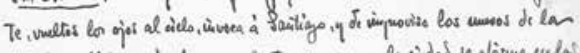

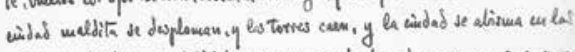

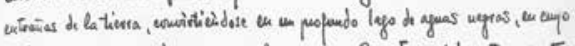

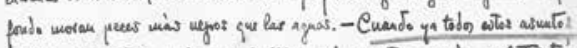

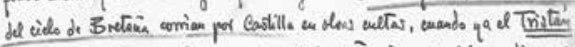

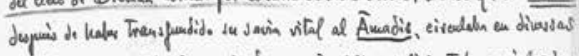

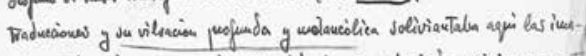

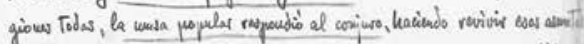

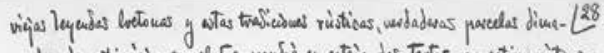

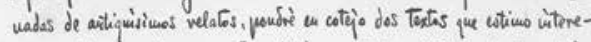

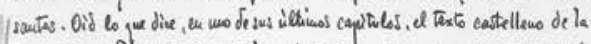

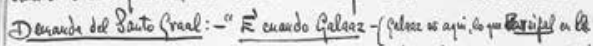

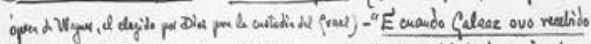

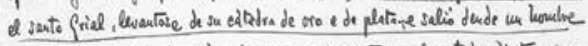

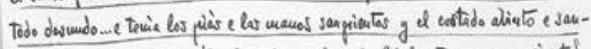

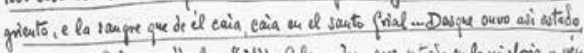

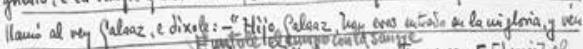

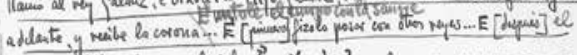

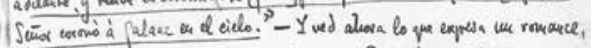

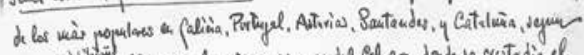

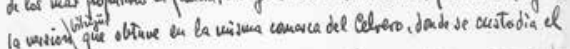
saprado vaso:

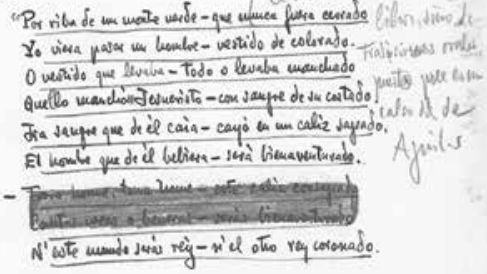

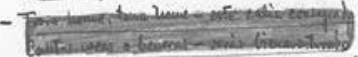

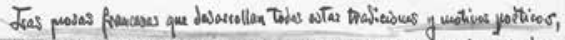

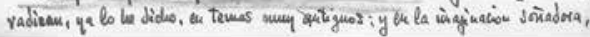

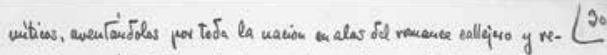

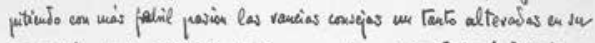

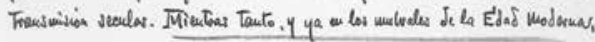

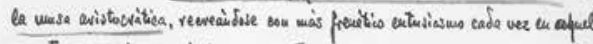

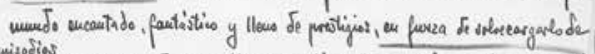

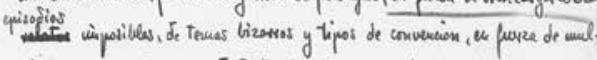

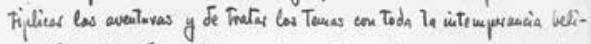

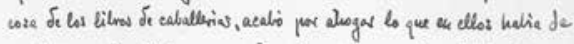

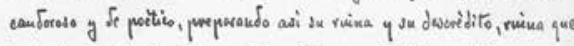

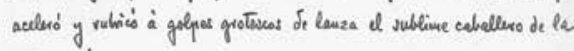
Triste Figuras.

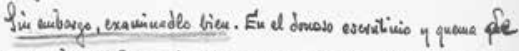

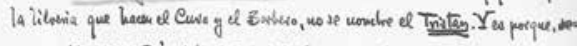

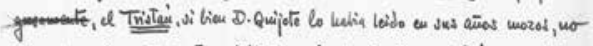

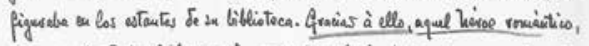

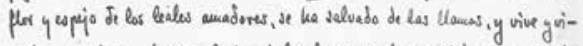

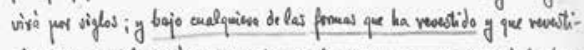

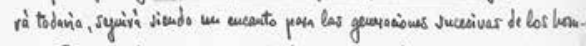
hes. Pergue end mascilloso cuento de anor hay elge permaneite, algo que

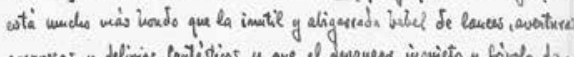

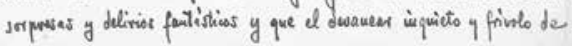
un mando cabollerisico y gelacte oreado por las troveros ded Ninte de Fran- 


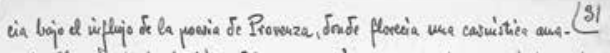

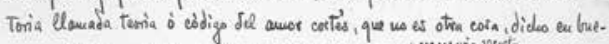

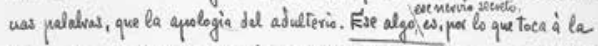

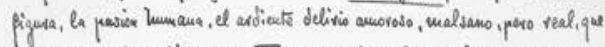

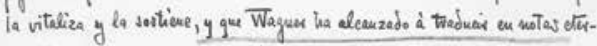

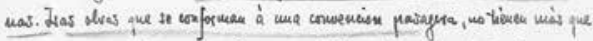

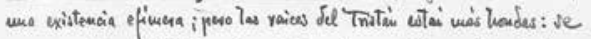

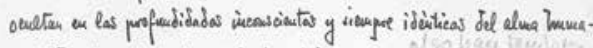

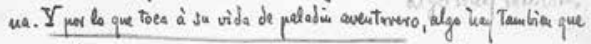

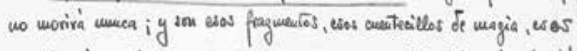

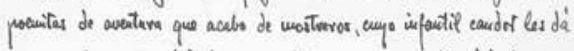

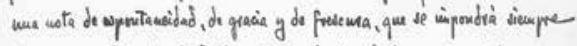

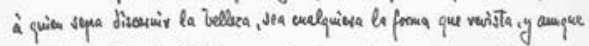

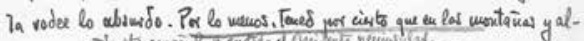

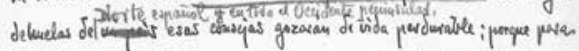

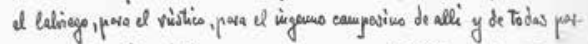
Tes, no hay uada mist hesmosto que lo que no axiste. Y reeso aciente.

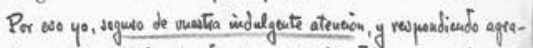

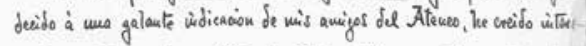

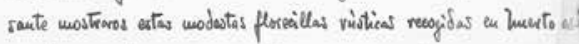

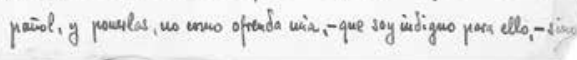

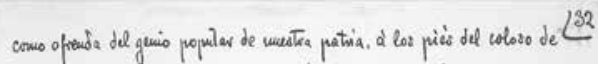
Bayreuth, qae aento à das su exprecion definitiva al inmortal polcua que consagua las myerias del anor y de la muevte. 